\title{
TERRAS RARAS: TABELA PERIÓDICA, DESCOBRIMENTO, EXPLORAÇ̃̃O NO BRASIL E APLICAÇÕES
}

\author{
Paulo C. de Sousa Filho ${ }^{\mathrm{a}, *, \odot}$, Ayla R. B.S. Galaço ${ }^{\mathrm{b}}$ e Osvaldo A. Serra ${ }^{\mathrm{b}, *}$ \\ a'Departamento de Química Inorgânica, Instituto de Química, Universidade Estadual de Campinas, 13083-970 Campinas - SP, Brasil \\ ${ }^{b}$ Departamento de Química, Faculdade de Filosofia, Ciências e Letras de Ribeirão Preto, Universidade de São Paulo, 14040-901 \\ Ribeirão Preto - SP, Brasil
}

Recebido em 07/08/2019; aceito em 03/10/2019; publicado na web em 13/11/2019

\begin{abstract}
RARE EARTHS: PERIODIC TABLE, DISCOVERY, EXPLORATION IN BRAZIL AND APPLICATIONS. In the 150 years comprised between the discovery of yttrium (1794) and promethium (1947), the rare earth metals were an incomplete chapter and a stone in the shoe of the periodic classification of the chemical elements. This group of 17 elements with remarkable chemical similarity raised confusion on many brilliant scientists, including Mendeleev, and led to the consolidation of many theories in Chemistry, from atomic spectroscopy to quantum theory. Nowadays we know that the special properties of these elements arise from filling $4 \mathrm{f}$ orbitals, which results in unique spectroscopic, magnetic and catalytic behavior. Such properties make rare earths essential elements on optical devices, lasers, telecommunications and magnetic materials for sustainable energy. The importance of rare earths far exceeds the science and technology domains, reaching the same level of other strategic materials for energy and defense. Hence, this work presents a brief discussion about the historical path of the rare earth elements in the Periodic Table and about the exploration of these resources in Brazil, detailing some of the extractive activities since the $19^{\text {th }}$ century and some perspectives for future activities concerning this group of elements in Brazil.
\end{abstract}

Keywords: rare earths; lanthanoids; Periodic Table.

\section{INTRODUÇÃO}

As terras raras (TR) figuram no cenário acadêmico há mais de dois séculos e, durante esse período, evoluíram do status de curiosidades de laboratório ao de armas de embargo entre as potências econômicas da atualidade. Dessa forma, a importância das TR transcende os domínios científico e tecnológico e atinge patamares idênticos aos de outros materiais estratégicos aos campos de energia e defesa, sendo, portanto, um assunto intimamente relacionado à soberania de uma nação. ${ }^{1-7}$

Segundo a União Internacional de Química Pura e Aplicada (IUPAC), as Terras Raras compreendem um grupo de 17 elementos químicos, correspondendo a escândio (Sc), ítrio (Y) e os 15 elementos lantanídeos (La-Lu) ${ }^{8,9} \mathrm{~A}$ alteração recente da nomenclatura IUPAC, em inglês, de "lanthanides" e "actinides" para, respetivamente, "lanthanoids" e "actinoids", motivada pela possível confusão com os nomes de ânions que terminam em "ide" não se justifica em Português. ${ }^{10}$

A característica mais marcante das TR é o fato de que esse grupo de elementos apresenta propriedades químicas essencialmente idênticas, sendo que se observam apenas diferenças muito sutis na reatividade seus íons trivalentes $\left(\mathrm{TR}^{3+}\right)$ devido aos seus diferentes raios iônicos. ${ }^{1,45}$ Como consequência dessa similaridade, constata-se que as TR ocorrem na natureza invariavelmente associadas umas às outras, de modo que seus minerais normalmente consistem em misturas de "TR leves" (também chamadas de terras céricas, La-Eu) ou de "TR pesadas" (conhecidas como "terras ítricas", Gd-Lu e Y)., Além disso, da alta similaridade entre propriedades químicas também decorre o problema histórico envolvendo a separação e identificação desses elementos. Esse processo compreendeu os esforços de pesquisadores de ao menos seis países, com mais de cem anúncios de descobertas, que na verdade eram misturas não completamente separadas. Durante mais de 150 anos (período compreendido entre do

*e-mail: pcsfilho@unicamp.br; osaserra@usp.br ítrio em 1794 e a constatação do promécio em 1947, última das TR a ser efetivamente identificada), as TR foram um capítulo incompleto na classificação periódica dos elementos químicos. ${ }^{9,11}$ Mencione-se, ainda, que uma grande fração da tecnologia de separação de TR que se atingiu ao longo do século XX é diretamente devida ao Projeto Manhattan, em que se realizava a separação desses elementos sobre resinas de troca de íons com o intuito de se obterem modelos para a separação de actinídeos, potenciais combustíveis nucleares. ${ }^{1,2,12-15}$ Atualmente, a separação desses elementos se processa explorando-se as pequenas diferenças de afinidade frente a agentes complexantes, sobretudo através de técnicas de extração por solvente, em decorrência da alteração do tamanho tamanhos dos íons ao longo da série., ${ }^{2,16}$

Apesar da alta similaridade química entre si, as TR apresentam propriedades que as tornam únicas com respeito aos demais elementos, o que é consequência de configurações eletrônicas muito particulares. Especificamente, os lantanídeos possuem configurações envolvendo elétrons $4 f$, que se encontram no interior dos átomos e, como consequência, são pouco afetados pelo ambiente químico em que os íons se encontram. ${ }^{1,17}$ Dessa forma, as TR conservam em seus compostos no estado condensado as propriedades observadas em átomos livres, fato que não é observado em nenhum outro grupo de elementos. Assim, além de terem constituído um grande desafio às teorias quânticas que se desenvolveram ao longo do século XX, as configurações eletrônicas $4 f$ associadas aos lantanídeos lhes conferem propriedades únicas com relação à absorção e emissão de luz, bem como ao comportamento magnético. ${ }^{18}$ Tais propriedades estão no cerne de suas mais finas aplicações (Figura 1), como a composição de ímãs permanentes de alta eficiência (aplicados em geradores eólicos, discos rígidos, autofalantes, dínamos etc. $)^{19,20}$ e de materiais luminescentes (aplicados em lâmpadas fluorescentes compactas, lâmpadas de LEDs, displays, marcadores, lasers etc. . ${ }^{21-23}$ Além disso, as propriedades das TR permitem aplicações na composição de baterias para veículos híbridos, ${ }^{24,25}$ catalisadores para o crackeamento do petróleo, ${ }^{25,26}$ catalisadores para a redução de emissões automotivas, ${ }^{27-29}$ vidros especiais, polimento fino de superfícies, cerâmicas de alta resistência, entre outras..$^{1-3,30,31}$ Pode-se mencionar, 
(a)

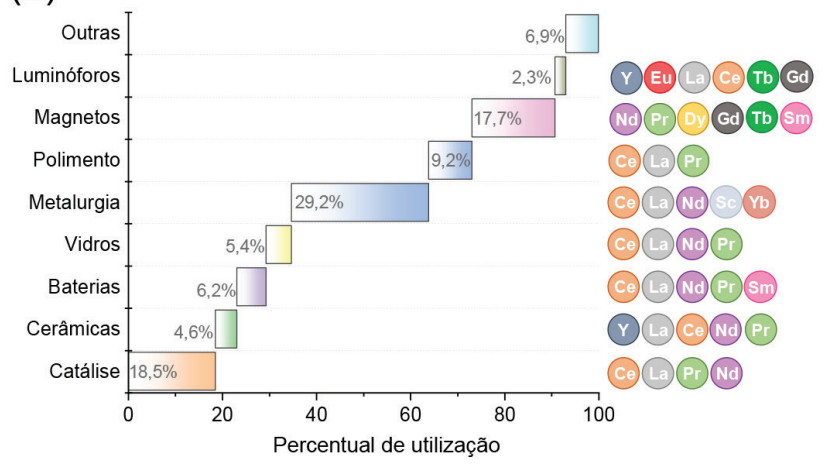

(b)

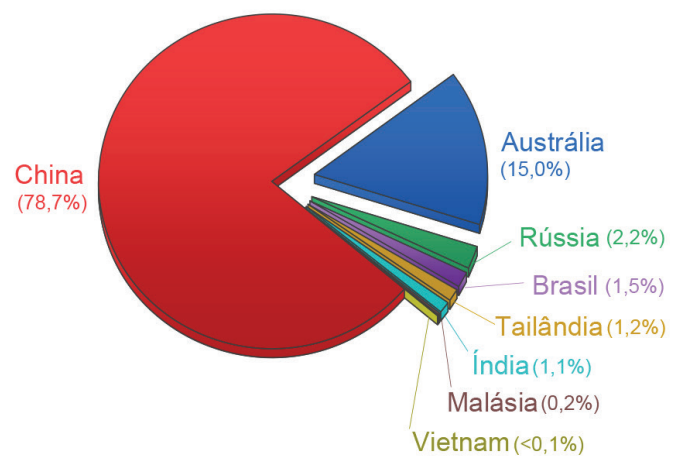

Figura 1. (a) Algumas das principais aplicações das TR, com seus respectivos percentuais de utilização (em termos do volume total) e (b) percentuais de produção de TR por diferentes países ${ }^{30,31}$

ainda, que várias dessas aplicações têm importância ímpar na área de defesa tais como, por exemplo, para comunicação e amplificação de sinais (detectores, radares, sonares e equipamentos de posicionamento global), motores elétricos e estocagem de energia em veículos militares, óculos de visão noturna, lasers como armas ou miras, armas guiadas de precisão, entre outros. ${ }^{32}$

Essa grande diversidade de aplicações tornou-se possível a partir da década de 1950 com o aprimoramento das técnicas de separação, permitindo a obtenção de TR cada vez mais puras em quantidades cada vez maiores. Assim, há mais de meio século as TR deixaram de ser apenas o rodapé das tabelas periódicas e passaram a assumir papéis centrais nas políticas ambientalmente amigáveis, pois são elementos diretamente relacionados a quatro dos principais eixos de crescimento sustentável, tais como geração de energias limpas, maiores eficiências em estocagem e conversão de energia, redução dos índices de poluição e otimização de recursos não renováveis. ${ }^{18-29}$ Com isso, a disponibilidade desses elementos torna-se uma espécie de gargalo para a pesquisa, desenvolvimento e implementação de novas tecnologias, ${ }^{33-35}$ de modo que, há alguns anos, é crescente a mobilização internacional com relação ao suprimento de TR, num mercado vastamente dominado pela China (Figura 1). ${ }^{36}$

As reservas de TR ao redor do globo são estimadas em aproximadamente 132.000.000 ton (em termos de óxidos de TR), sendo que a China é detentora de aproximadamente um terço desse valor (Figura 2). O Brasil possui reservas expressivas de TR (22.000.000 ton em óxidos de TR), assim como Vietnam e Rússia, ${ }^{31}$ mas a China ainda é isoladamente o principal centro na exploração e separação de TR. Com um intenso empenho científico na exploração de seus recursos e com uma política de processamento de TR com pouca ou nenhuma cautela ambiental, a China foi capaz de fornecer TR em elevadas quantidades e a um custo extremamente baixo a partir da década de 1990. Com isso, a maior parte dos produtores mundiais foi suprimida e suas indústrias de processamento mineral foram fechadas, de modo que, a partir de 2002, praticamente toda a TR empregada industrialmente ao redor do globo tinha procedência chinesa. Assim, apenas com a crise das TR em 2009-2010, países como EUA, França e Austrália constataram uma perda do savoir-faire envolvido nas técnicas de exploração de TR em áreas como química, geologia e engenharias de minas e produção, sendo que a recuperação dessas competências humanas tende a levar décadas. Alie-se a esse cenário a grande dificuldade de atração de grandes investidores ao mercado das TR, que representam apenas algo em torno de 1/10000 da produção mundial de metais, ou seja, menos que $3 \%$ do valor associado apenas à metalurgia do cobre, por exemplo. Os valores pouco expressivos não geram a atratividade esperada por grandes grupos mineradores, dificultando ainda mais as ações no sentido de reativar a produção de TR.

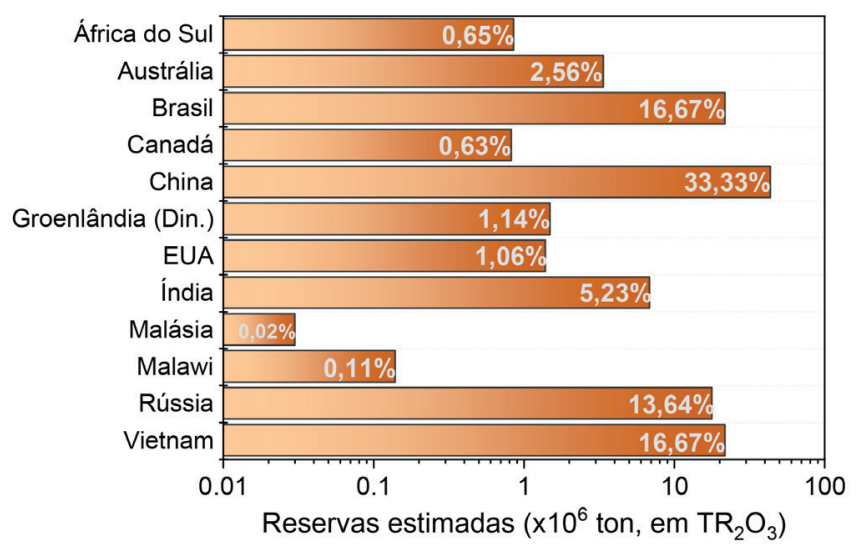

Figura 2. Estimativas das principais reservas de TR (em termos de óxidos) ao redor do mundo e respectivas percentagens em termos do total mundial $(132.000 .000 \text { ton })^{31}$

Como resultado, a questão das TR ao redor mundo tem, nos últimos anos, norteado discussões em parlamentos e levado à elaboração de planos de ação, muitos sem consequência prática. No Brasil, não é diferente. Observa-se um cenário a priori promissor, pois o Brasil possui grandes reservas de TR (Figura 2) e, indiscutivelmente, é produtor de resultados de alto nível em diferentes campos de pesquisa envolvendo esse grupo de elementos. Contudo, esse cenário contrasta com o fato de que o Brasil tem produção quase inexpressiva de TR e é totalmente dependente da China para aquisição das baixas quantidades que consome, num momento em que se afirma que o grau de desenvolvimento de uma nação é medido pelo consumo de TR para aplicações em tecnologia de ponta. ${ }^{1,3}$ A relativa abundância das TR em território brasileiro não tem favorecido o crescimento do país no campo da produção e aplicação desses elementos, como consequência da carência de políticas sólidas abarcando pesquisa, desenvolvimento e confecção de produtos finais em torno de temáticas específicas no campo das TR.

Contudo, subaproveitamento de recursos e gestão questionável não são fatores recentes na história brasileira da exploração das terras raras e nem particulares a esses metais. Dessa forma, o presente texto apresenta uma breve discussão acerca da trajetória histórica das TR na Tabela Periódica e da exploração desses recursos no Brasil, com o apontamento das principais atividades de extração a partir do século XIX e as algumas perspectivas para as futuras atividades do país no campo desse grupo de elementos.

\section{DESCOBRIMENTO}

No verão de 1995, reuniram-se no El Escorial em Madrid, para 
ministrarem um dos temas dos "Cursos de Verano" da Universidade Complutense, renomados cientistas amantes das Terras Raras, cujas participações foram publicadas em 1998 no livro denominado "Rare Earths" editado por Regino Saez-Puche e Paul Caro. ${ }^{3}$ Um dos mais belos capítulos do livro, intitulado "Discovery and Separation of the Rare Earth" é de autoria de Lauri Niinistö, finlandês, cientista e historiador da ciência. Desse capítulo retiramos a maioria das informações a seguir descritas. Outras literaturas ${ }^{9,11,37}$ são sugeridas aos leitores interessados na história do descobrimento das TR.

Em 1787, Carl Axel Arrhenius (tenente do exército sueco e geólogo amador) encontrou um mineral escuro e pesado, numa pedreira no vilarejo de Ytterby a $30 \mathrm{~km}$ de Estocolmo. O mineral foi enviado para vários analistas, sendo nomeado "ytterbite" por Bengt Reinhold Geijer que determinou sua densidade em $4,2 \mathrm{~g} \mathrm{~cm}^{-3}$ considerando-a formada por tungstênio e bário, recentemente descobertos. Cinco anos mais tarde, 1792, Johan Gadolin da Universidade de Turku (naquela época pertencente à Suécia, atualmente na Finlândia) iniciou o estudo da "pedra preta de Ytterby". Em 1794, Gadolin concluiu que a "pedra de Ytterby" era composta por uma nova "terra" (óxido), a qual denominou "yttria" (Y), associada a sílica, óxido de ferro e alumina. Na realidade o alumínio foi confundido com o berílio (Be), que viria a ser descoberto posteriormente por Nicolas Vauquelin em 1798. A "ytterbite" (iterbita) foi depois denominada gadolinita em homenagem a Gadolin e possui composição $\mathrm{Be}_{2} \mathrm{FeY}_{2} \mathrm{Si}_{2} \mathrm{O}_{10}$. O elemento denominado ítrio, mostrou-se, após mais de 100 anos de pesquisas, ser formado de dez elementos TR (Figura 3 ) como veremos adiante.

Em 1751, Axel Frederik Cronstedt reportou um mineral o qual chamou de "pedra pesada de Bastnas". O mineral não foi investigado até 1803, quando foi analisado independentemente por Martin
Heinrich Klaproth e por Wilhelm Hisinger, esse juntamente com o jovem Jöns Jacob Berzelius. Ambos determinaram que o mineral possuía a mesma nova "terra", que foi chamada de ocroíta por Klaproth. Hisinger e Berzelius denominaram essa "terra" de "ceria" (céria) (Ce) e o mineral de "cerita", nome relacionado ao planetoide Ceres, descoberto cerca de dois anos antes.

Carl Gustaf Mosander, assistente e posteriormente sucessor de Berzelius na "Karolinska Medico-Chirurgical Instiute" em Estocolmo, retomou os estudos com a "cerita" que o levaram ao descobrimento do lantânio (La) em 1839. Mosander anunciou em 1842 a descoberta do didímio (que em 1885 seria comprovado por Carl Auer von Welsbach como sendo uma mistura de dois novos elementos, Nd e Pr). Ainda em 1843, Mosander com a ajuda de Berzelius anunciava a presença de dois novos elementos na céria, o térbio $(\mathrm{Tb})$ e o érbio $(\mathrm{Er})$.

Com a organização periódica dos elementos por Mendeleev em 1869 , a busca por novos elementos foi retomada com afinco. $\mathrm{Na}$ Suécia, o berço das TR, na Universidade de Upsala, Per Theodore Cleve e Lars Frederik Nilson relatam a descoberta de escândio (Sc), hólmio (Ho) e túlio (Tm) em amostras de gadolinita em 1879. Curiosamente, Cleve e Nilson nasceram em 1840, ano em que nasceram também Rodin e Monet. No mesmo ano, após cuidadoso trabalho espectroscópico Emile LeCoq Boisbaudran, na França, descobre o samário (Sm) e o disprósio (Dy) em 1886, em amostras de céria. Ainda em amostras de céria, Jean Charles Marignac descobre o gadolínio (Gd) em 1880. Já no século XX, Eugène-Anatole Demarcay em 1901 descobre o európio (Eu) e em 1907 Georges Urbain descobre o Lutécio (Lu). Restava o elemento 61 localizado entre o neodímio e o samário. Marinsky, em 1947 encontrou o isótopo 147 em produtos de

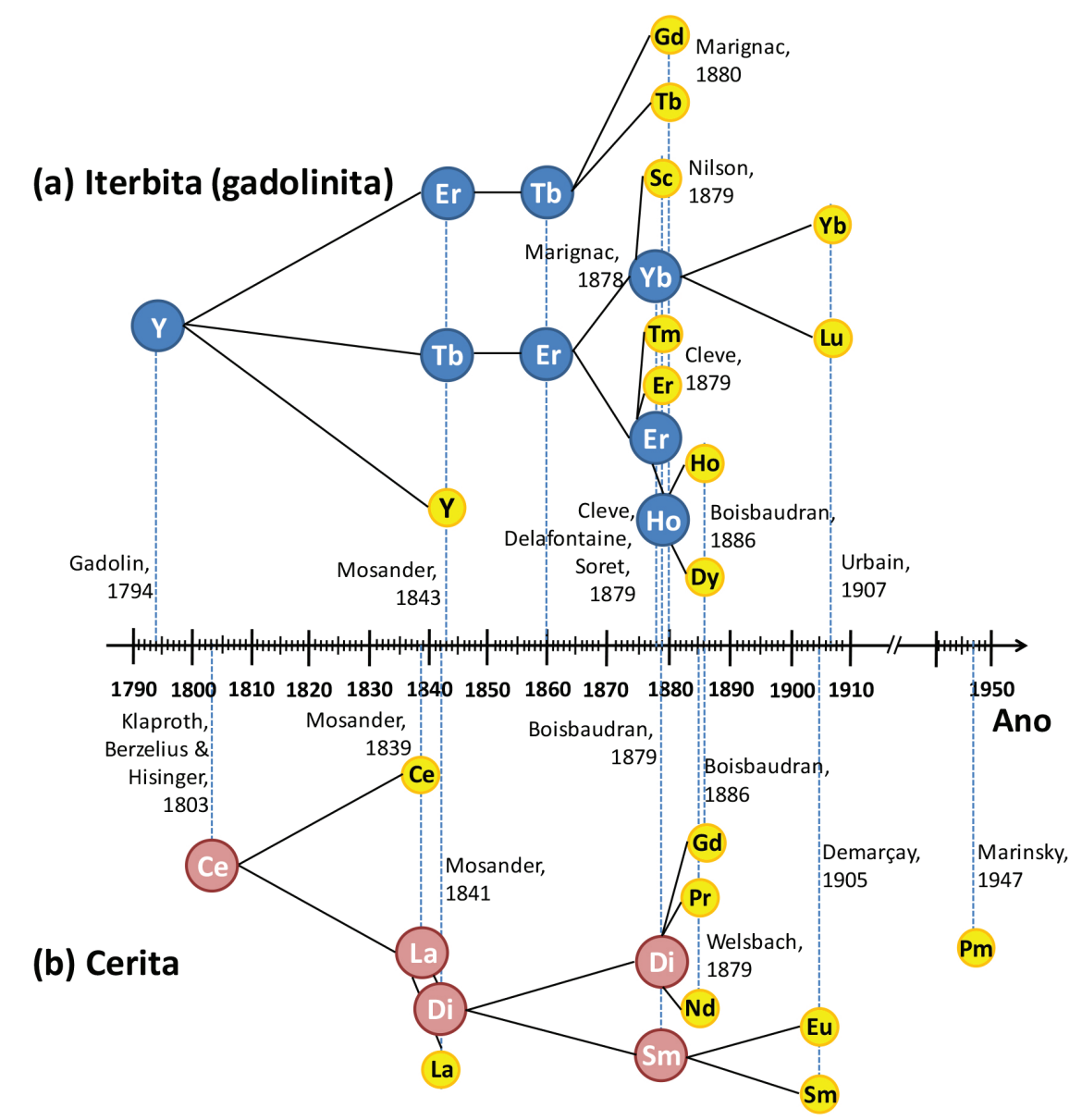

Figura 3. Cronologia histórica do descobrimento das TR: (a) das terras ítricas a partir da iterbita (gadolinita) e (b) das terras céricas a partir da cerita. (Reproduzido da Ref. 9) 
fissão nuclear do urânio e o elemento foi denominado promécio (Pm). Partindo de 20 ton de óxidos de terras raras provenientes de apatita (6000 ton), em 1965 Olavi Erämetsä, em Helsinki, isolou 82 mg de $\mathrm{Pm}_{2} \mathrm{O}_{3}$ contendo o isótopo radioativo 147. A saga da descoberta das TR iniciada em 1794 por um finlandês (J. Gadolin) se encerra por outro finlandês (O. Erämetsä) em 1965!

\section{AS TERRAS RARAS E A TABELA PERIÓDICA}

Em 1869, Mendeleev apresentou pela primeira vez sua elegante classificação dos elementos químicos conhecidos organizados em termos de seus pesos atômicos, com uma disposição de 6 colunas e 19 linhas. ${ }^{38,39}$ À época da primeira Tabela Periódica de Mendeleev, conheciam-se seis elementos TR: o ítrio (então grafado Yt), o cério (Ce), o lantânio (La), o didímio (Di, que posteriormente provou-se ser uma mistura de praseodímio e neodímio), o térbio ( $\mathrm{Tb}$, originalmente chamado érbio) e o érbio (Er, originalmente batizado de térbio).$^{9,11}$ Mendeleev acomodou apenas cinco das TR até então descobertas (Yt, $\mathrm{Ce}, \mathrm{La}, \mathrm{Di}$ e Er) pela dificuldade em encaixar o comportamento químico desses elementos aos grupos de elementos até então existentes. Além disso, algumas inversões de posição na tabela (com respeito ao aumento do peso atômico de cima para baixo e da esquerda para direita) desapareceriam se algumas das TR fossem removidas, tornando confusa sua classificação junto aos demais elementos. Nesse sentido, por exemplo, Lothar Meyer simplesmente excluiu as TR de sua classificação periódica em 1870 , por achar que não se tratavam efetivamente de elementos químicos..$^{38,39}$

As dificuldades de se incluir as TR no recém-proposto sistema periódico de Mendeleev têm origem nas inconsistências das massas atômicas inicialmente determinadas para esses elementos, tanto por erros nos cálculos (Mendeleev assumiu inicialmente que o número de oxidação mais comum das TR fosse $2+$ ), quanto pelo fato de que os chamados "elementos" eram, na verdade, misturas. Em seu "Sistema Natural dos Elementos" publicado em 1871 (que apresenta os grupos e períodos com uma disposição mais próxima da utilizada hoje), ${ }^{40}$ Mendeleev posicionou as TR em grupos separados, sendo Yt, Di e Er no grupo III (dos elementos que formam óxidos de fórmula " $\mathrm{R}_{2} \mathrm{O}_{3}$ ") e Ce e La no grupo IV (dos que formam óxidos do tipo " $\mathrm{RO}_{2}$ ")
(Figura 4). Contudo, a posição das TR na Tabela Periódica ainda era uma questão em aberto para Mendeleev, que colocou um ponto de interrogação à esquerda dos símbolos desses elementos em sua tabela de 1871. O interesse de Mendeleev na acomodação adequada das TR na Tabela Periódica era tamanho que, tal como se menciona, ${ }^{11} \mathrm{em}$ 1870 o químico russo teria solicitado ao reitor da Universidade de São Petersburgo amostras de diferentes "minerais raros" tais como rutilo, ilmenita, zirconita, alanita, cerita e eschinita para a realização de seu trabalho científico. Todos esses minerais contêm ou são acessórios a minerais contendo TR, sugerindo que Mendeleev buscava efetivamente investigar as propriedades desses elementos. Entretanto, nos anos subsequentes Mendeleev decide abandonar suas pesquisas sobre as TR e seu posicionamento na Tabela Periódica quando, em um curto período de tempo, constata-se que muitos dos chamados "elementos" eram misturas (com as descobertas de $\mathrm{Pr}$, Nd e Sm a partir do didímio, do Gd a partir do térbio, e do Yb, Tm e Ho a partir do érbio, Figura 3).9.37

Ao início do século XX, somente Sc, Y, La e Ce tinham sido acomodados com clareza nas Tabelas Periódicas. O elemento seguinte (Di, posteriormente $\mathrm{Pr}$ e $\mathrm{Nd}$ ) não apresentava comportamento pentavalente como sua posição em princípio indicava. À época, por exemplo, já se sugeria que os elementos do chamado "grupo do cério" (i.e., as TR) também poderiam apresentar comportamentos parecidos entre si, tais como nas tríades $\mathrm{Fe} / \mathrm{Ni} / \mathrm{Co}, \mathrm{Pd} / \mathrm{Rh} / \mathrm{Ru}$ e $\mathrm{Pt} / \mathrm{Ir} / \mathrm{Os}$, que possuem peso atômico praticamente constante e possuem química relativamente similar (sendo posicionados nos mesmos grupos nas tabelas de Mendeleev) (Figura 4). No entanto, a não acomodação das TR no sistema periódico nascente e as inversões necessárias na ordem de peso atômico para alocar alguns elementos junto aos seus similares (e.g. Ar e K, Co e Ni, e Te e I) passaram a colocar em dúvida a lei periódica de Mendeleev.

Frente a essas dificuldades, várias teorias foram progressivamente propostas. Por exemplo, William Crookes, especialista em espectroscopia atômica e um dos inventores dos tubos a vácuo, propôs o conceito de meta-elementos para explicar o comportamento das TR. ${ }^{41}$ Segundo esse conceito, os elementos químicos seriam combinações de diferentes meta-elementos, caracterizados por pequenas variações no seu peso atômico, sendo que o peso atômico de um elemento seria a média dos pesos atômicos de seus meta-elementos componentes.

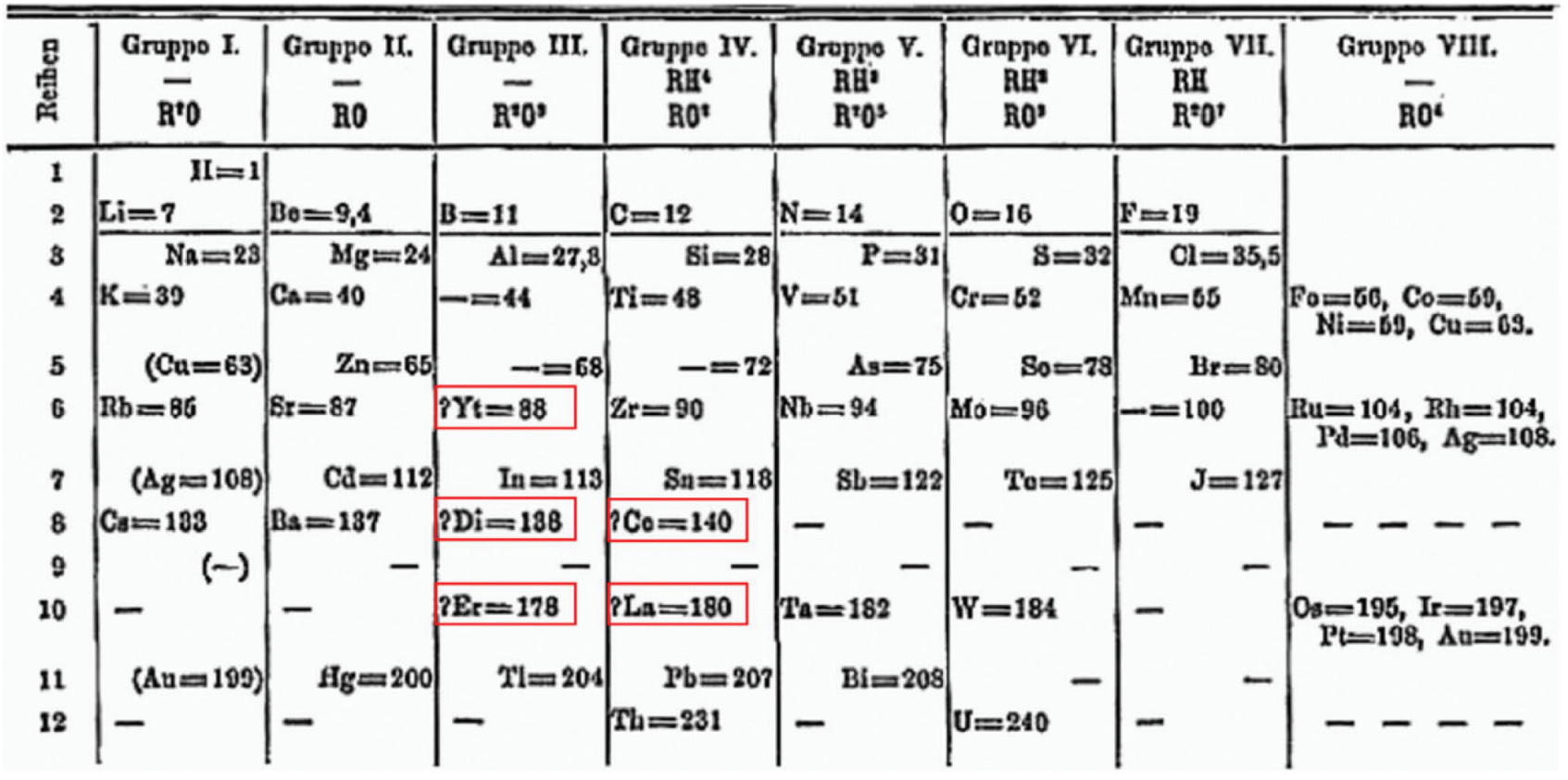

Figura 4. Versão da Tabela Periódica de Mendeleev publicada no Liebigs Ann. Chem. em 1871, ${ }^{40}$ com destaque para as TR conhecidas à época (Yt=ítrio; Di=didimio; Er=érbio; Ce=cério; e La=lantânio) 
Embora essa teoria possa ser considerada como um embrião do conceito atual de isótopos, o conceito de meta-elementos de Crookes provou-se errado através de estudos de espectros atômicos realizados por Georges Urbain. Posteriormente, os químicos passaram a utilizar o conceito de grupos intraperiódicos para acomodar alguns elementos nas tabelas periódicas da época. Nesse caso, agrupavam-se coletivamente diferentes elementos em grupos intermediários aos grupos de comportamento bem definido, tal como nas tabelas de Jan Willem Retgers (1895) e Bohuslav Brauner (1902). Uma das mais famosas disposições com grupos intraperiódicos é a de Stefan Meyer (que não possui relação com Lothar Meyer), ${ }^{42}$ em que as TR (Seltene Erden em alemão, referindo-se na verdade aos lantanídeos) são posicionadas como um grupo intermediário abaixo de Y e Zr (Figura 5). Além disso, note-se nessa tabela os nomes Ad (aldebarânio) e Cp (cassiopeio) no lugar de itérbio (Yb) e lutécio ( $\mathrm{Lu}$ ), ilustrando a disputa pelos nomes desses dois elementos entre os descobridores da escola alemã (a de Meyer) frente aos nomes sugeridos pelos descobridores da escola francesa (de Marignac e Urbain).

Ao início dos anos 1910, persistia a controvérsia sobre quantos seriam os lantanídeos e sobre qual seria seu posicionamento adequado na classificação periódica dos elementos. Nessa época, os conceitos de núcleo atômico (modelo de Rutherford, 1911) e, posteriormente, das órbitas de elétrons (modelo de Bohr, 1913) já haviam sido introduzidos. Frente ao sucesso da teoria de Bohr em explicar as linhas de emissão do átomo de hidrogênio, Henry Moseley foi impulsionado a estudar uma correlação similar entre a frequência dos raios $\mathrm{X}$ emitidos por diferentes elementos químicos e a quantidade de cargas positivas em seu núcleo. À época, o conceito de número atômico (Z, de Zahl, literalmente "número" em alemão) referia-se basicamente à posição numérica do elemento no ordenamento periódico. Em 1913,
Moseley foi capaz de demonstrar haver uma relação linear entre o número atômico e a raiz quadrada da frequência dos raios $\mathrm{X}$ emitidos pelos átomos de todos os elementos conhecidos entre o alumínio e o ouro. Além de provar a clara relação entre o número atômico e a carga positiva presente no núcleo dos átomos, o experimento de Moseley demonstrou que poderiam existir apenas 16 elementos químicos entre o bário e o tântalo, confirmando pela primeira vez em aproximadamente 120 anos que o número de elementos lantanídeos era 15. ${ }^{11,43}$ Esse havia sido o número previsto na Tabela Periódica de Julius Thomsen em 1895 (Figura 6). ${ }^{38,39,44}$

Aos 25 anos, Henry Moseley demonstrou que o número atômico (e não o peso atômico) era o fator dominante na descrição das tendências periódicas, explicou as inversões de $\mathrm{Ar} / \mathrm{K}, \mathrm{Co} / \mathrm{Ni}$ e Te/I, postulou a existência dos elementos $43,61,72$ e 75 (que viriam a ser descobertos pouco depois) e confirmou o número de elementos TR. Moseley não sobreviveria para ser elegível ao Prêmio Nobel de Física por essas descobertas nem para ver seu antigo colega de laboratório Niels Bohr ser laureado em 1922:11,45 Moseley fora enviado aos frontes da Primeira Guerra Mundial, sendo morto na Campanha de Galípoli (Turquia) em $1915 .{ }^{43}$ Niels Bohr, apesar de sua formação física, tinha grande interesse em utilizar suas proposições sobre a estrutura atômica para explicar as propriedades químicas e a classificação periódica dos elementos. No início dos anos 1920, Bohr constata que o número atômico de um elemento é igual ao número de elétrons que se movem ao redor do núcleo de um átomo neutro, e que o sistema periódico poderia ser explicado com base em configurações eletrônicas. Na visão de Bohr, os lantanídeos correspondiam ao preenchimento final do quarto nível quântico, que comportaria 32 elétrons ao invés de 18. Utilizando argumentos quânticos, Bohr é o primeiro a explicar a similaridade química entre as TR e a diversidade de seu

\section{Tabelle I. Periodisches System der Elemente.}

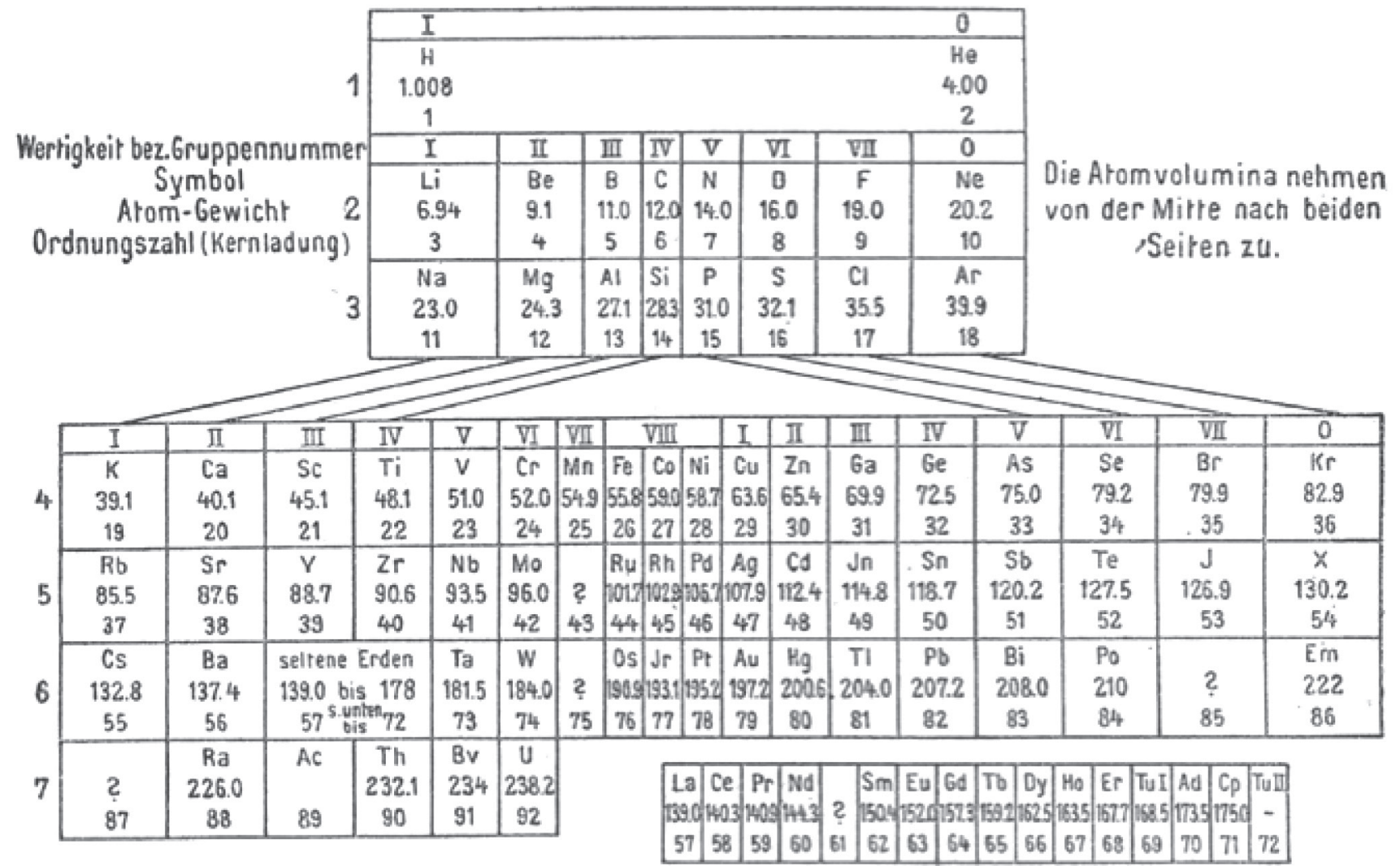




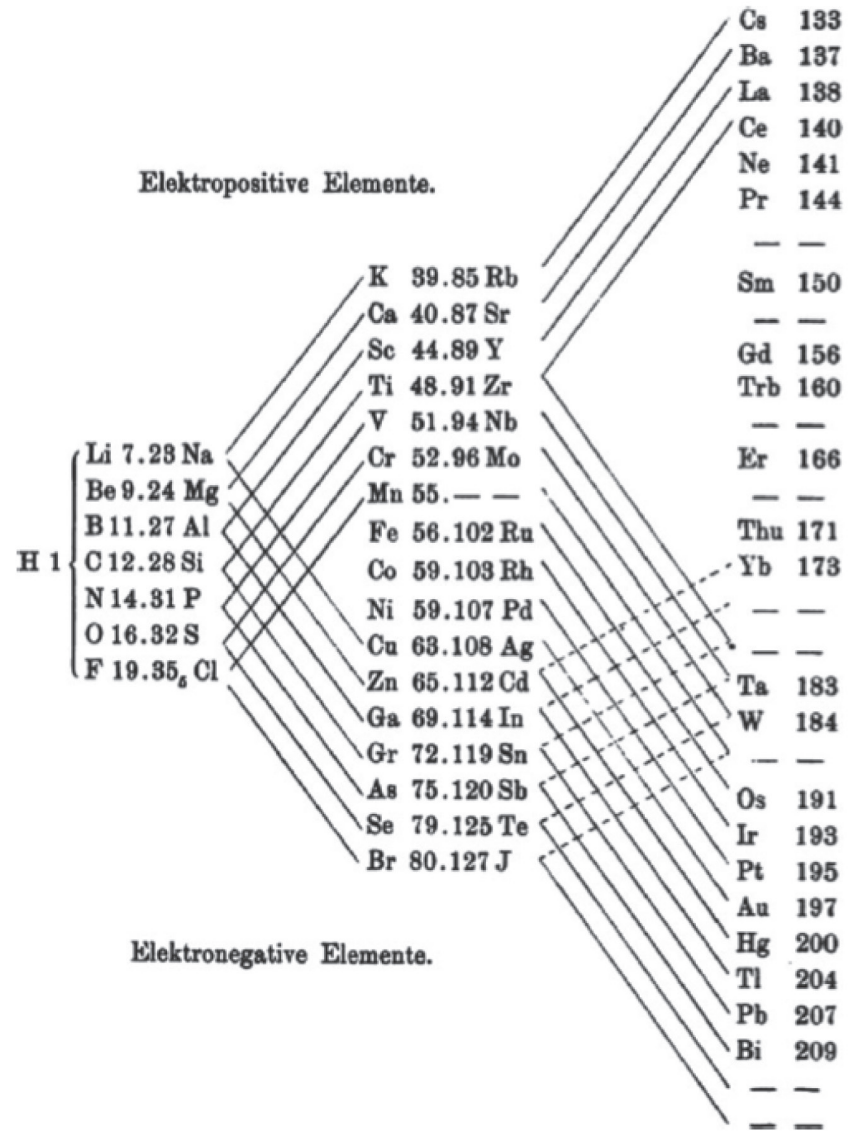

Figura 6. Tabela Periódica proposta por Julius Thomsen (publicada no Zeitschrift für Anorganische Chemie em 1895), ${ }^{38,39,44}$ com disposição piramidal na horizontal dos elementos, em que as TR foram acomodadas como intergrupo sem correlação com os elementos anteriores. Uma versão similar a esta Tabela Periódica foi utilizada por Niels Bohr em sua apresentação pelo Prêmio Nobel ${ }^{45}$

comportamento magnético. Em sua palestra pelo Prêmio Nobel de 1922, Bohr menciona que "a peculiar família de elementos do sexto período, conhecida como Terras Raras... possui maior similaridade química mútua do que os elementos do grupo do ferro", o que se deveria ao fato de que esses elementos possuem "grupos de elétrons localizados mais ao interior do átomo". ${ }^{45} \mathrm{Na}$ mesma apresentação, Bohr utiliza como representação da lei periódica uma tabela muito similar à de Thomsen, ${ }^{44}$ em que os blocos d e f são acomodados como intergrupos sem uma correlação direta com outros elementos dos grupos anteriores (Figura 6).
O primeiro a utilizar esse conceito de intergrupos em uma disposição longa em grupos e períodos foi Alfred Werner, químico suíço e pai da Química de Coordenação. ${ }^{46}$ A tabela de 1905 de Alfred Werner possui um arranjo muito similar ao utilizado atualmente (Figura 7), ${ }^{47}$ sendo que os elementos dos f e d são acomodados na forma de blocos intermediários entre os elementos s e p. Apesar de prever um número incorreto de lantanídeos (16 ao invés de 15), Werner foi o primeiro a supor a existência de uma segunda série de elementos pesados com características análogas, que viria a ser completa pela descoberta dos elementos transurânicos nas décadas seguintes. ${ }^{48}$ Outro erro na disposição proposta por Werner é a inversão entre Pr e Nd. Werner supôs que esse par seria análogo a Ni/Co (que estão invertidos com relação à ordem em termos de peso atômico), já que o praseodímio forma sais verdes (tal como o níquel(II)), enquanto o neodímio forma compostos violetas (similares aos sais hidratados de cobalto(II)). Por fim, a mescla das constatações de Moseley e Bohr sobre a dependência das tendências periódicas com o número atômico com a disposição em intergrupos proposta por Werner (com as devidas correções) gerou o arranjo mais popular da Tabela Periódica.

Na Tabela Periódica da IUPAC, já em sua versão de 2018, os elementos do bloco f são dispostos abaixo do grupo principal, sendo que os espaços que seguem o bário e o rádio possuem apenas indicações para os blocos $4 \mathrm{f}$ e $5 \mathrm{f}$ subsequentes. ${ }^{49}$ Além de dar a impressão de que os lantanídeos e actinídeos são notas de rodapé da Tabela Periódica, essa representação sugere que esses dois grupos de elementos estão inteiramente contidos no grupo 3 da Tabela Periódica. Essa representação, portanto, equivaleria a dizer que o bloco f estaria contido no bloco d da Tabela Periódica, o que não é coerente sob diversos aspectos. Como alternativa, várias Tabelas Periódicas em livros texto de química colocam La ou Lu abaixo do ítrio, depois do bário, com alguma indicação para a sequência abaixo do corpo principal.

As três representações acima têm gerado discussões ainda recentemente, ${ }^{11}$ mostrando que o posicionamento das TR na Tabela Periódica é um ainda é um capítulo inacabado na classificação dos elementos químicos. A capa do livreto de programa e resumos da $2^{\text {nd }}$ International Conference on f-Elements, realizado em Helsinki em 1994 (em comemoração do segundo centenário da descoberta do ítrio) apresenta, por exemplo, uma versão estilizada da Tabela Periódica na visão dos "terrarraristas" (Figura 8).

Embora esse esquema da Tabela Periódica seja bastante atrativo aos "terrarraristas" por destacar a posição das TR, o posicionamento de La e Ac abaixo do Y também pode ser questionado. Primeiramente, analisando-se as tendências ao longo do grupo 3 da Tabela Periódica (e comparando-se com as tendências geralmente observadas entre elementos das séries $4 d$ e $5 d$ ), percebe-se que a situação mais coerente compreende o posicionamento de Lu e Lr abaixo de Sc e Y. Para isso, basta verificarem-se as tendências entre as séries do quinto e

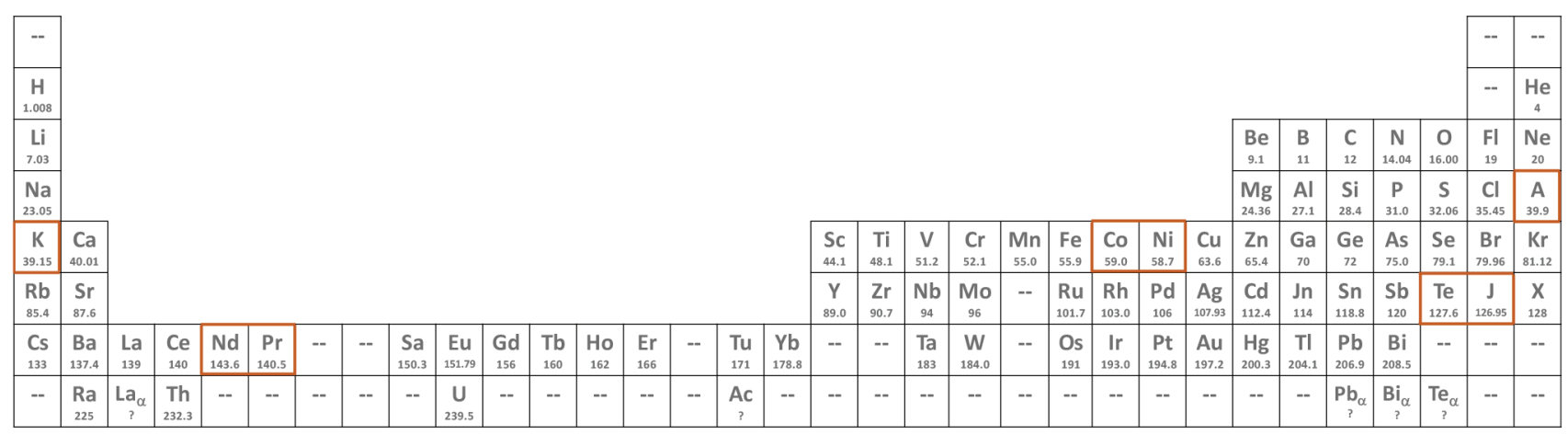

Figura 7. Reprodução do arranjo proposto por Alfred Werner em 1905 (ocupando a página 916 do volume 38 do Chemische Berichte em 1905), ${ }^{47}$ em que se propõe uma organização similar à atual (com os lantanídeos como um intergrupo) em disposição alongada. Os elementos circulados destacam as inversões de ordem de peso atômico (Ar/K, Co/Ni, Te/I e, na proposição de Werner, Nd e Pr) 


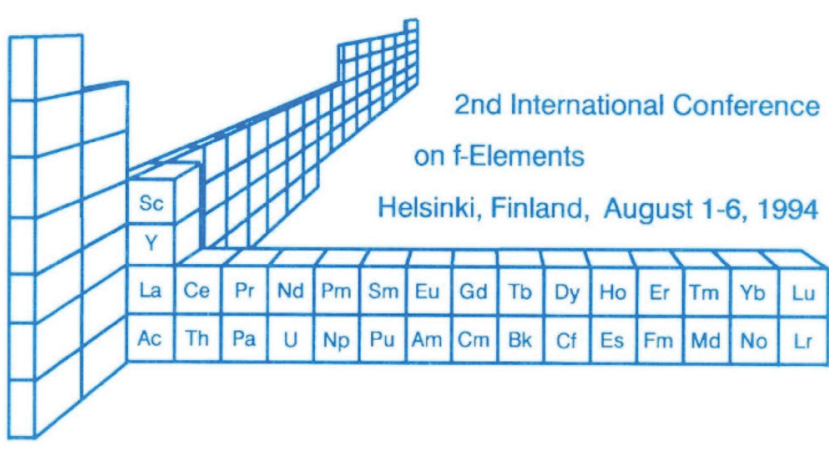

Figura 8. Capa do livreto de programa e resumos da $2^{\text {nd }}$ International Conference on f-Elements, realizada em Helsinki, Finlândia, de 1 a 6 de agosto de 1994

sexto períodos respeito a pontos de fusão, raios e volumes atômicos, estruturas cristalinas em temperatura ambiente, condutividade, eletronegatividade, entre outras propriedades. ${ }^{11}$ Comparando-se as mesmas propriedades para as sequências entre Sc-Y-La-Ac e Sc-Y-Lu-Lr, verifica-se que a segunda situação é a mais coerente com o comportamento observado com os demais membros dos mesmos períodos. Logo, tais tendências reforçam o formato em que os elementos a serem incluídos abaixo de Sc e Y devem ser Lu e Lr e não La e Ac. Em termos de configurações eletrônicas, tanto La como Lu apresentam configuração fundamental do tipo [Xe] $6 \mathrm{~s}^{2} 4 \mathrm{f}^{\mathrm{x}-1} 5 \mathrm{~d}^{1}$ (com $\mathrm{x}=1$ para La e $\mathrm{x}=15$ para $\mathrm{Lu}$ ). Ambos apresentam elétron diferenciador em um orbital d, mas considerando-se a regra de Madelung $(n+1)$, observa-se que o lantânio deve ser tratado como o primeiro elemento da série 4f, enquanto o Lu é o primeiro elemento da série $5 \mathrm{~d}$. Assim, o formato da Tabela Periódica mais coerente com as tendências químicas e configurações eletrônicas posiciona Lu e Lr como membros do grupo 3, indicando que lutécio (o último dos lantanídeos) e o laurêncio (o último dos actinídeos) são membros do bloco d. Portanto, La e Ac são os primeiros elementos do bloco f, nas séries $4 \mathrm{f}$ e $5 \mathrm{f}$, respectivamente. A Figura 9 mostra a Tabela Periódica com posicionamento Sc-Y-Lu-Lr em formatos alongado e condensado.

\section{PRIMÓRDIOS DA EXPLORAÇÃO DAS TERRAS RARS NO BRASIL}

O Brasil dispõe diferentes tipos de depósitos de TR, estimadas em um total de aproximadamente 22.000 .000 ton, ${ }^{31}$ embora grande parte desse volume corresponda a minerais de processamento não estabelecido ou consideravelmente complexo. Tais reservas compreendem minerais alcalinos intrusivos, carbonatitos, depósitos lateríticos, fluviais e costeiros. ${ }^{1,2,4,16}$ Dos minerais de TR presentes no Brasil, o que apresenta a maior facilidade de prospecção e processamento é a monazita, estando a ela relacionados os primórdios da exploração de TR no país.

A monazita é um ortofosfato das terras céricas e de tório, ocorrendo nos mais diversos ambientes geológicos como mineral acessório em rochas ígneas, metamórficas ou na forma de areias. ${ }^{16,50}$ Trata-se de um mineral relativamente denso $\left(4,6-5,4 \mathrm{~g} \mathrm{~cm}^{-3}\right)$, de lustro resinoso e com dureza variável entre 5,0 e 5,5 na escala de Mohs. O termo monazita tem origem no grego "monazeis", que significa "estar só", pois seus cristais normalmente ocorrem isolados em rochas ígneas pegmatitas. O conteúdo total de TR, bem como a distribuição das TR particulares e a quantidade de tório, depende de sua localização específica. Contudo, a monazita geralmente é composta de $70 \%$ em

\section{(a)}

\begin{tabular}{|c|c|c|c|c|c|c|c|c|c|c|c|c|c|c|c|c|c|c|c|c|c|c|c|c|c|c|c|c|c|c|c|}
\hline H & & & & & & & & & & & & & & & & & & & & & & & & & & & & & & & $\mathrm{He}$ \\
\hline Li & $\mathrm{Be}$ & & & & & & & & & & & & & & & & & & & & & & & & & B & C & $\mathbf{N}$ & 0 & $F$ & $\mathrm{Ne}$ \\
\hline $\mathrm{Na}$ & $\mathrm{Mg}$ & & & & & & & & & & & & & & & & & & & & & & & & & Al & Si & $\mathbf{P}$ & $S$ & Cl & $\mathrm{Ar}$ \\
\hline K & $\mathrm{Ca}$ & & & & & & & & & & & & & & & Sc & $\mathrm{Ti}$ & 1 & & & $\mathrm{Fe}$ & Co & $\mathrm{Ni}$ & $\mathrm{Cu}$ & $\mathrm{Zn}$ & Ga & $\mathrm{Ge}$ & As & Se & $\mathrm{Br}$ & $\mathrm{Kr}$ \\
\hline Rb & $\mathrm{Sr}$ & & & & & & & & & & & & & & & $Y$ & $\mathrm{Zr}$ & $\mathrm{N}$ & & & Ru & Rh & $\mathbf{P d}$ & $\mathrm{Ag}$ & $\mathrm{Cd}$ & In & Sn & $\mathrm{Sb}$ & Te & I & Xe \\
\hline Cs & $\mathrm{Ba}$ & La & $\mathrm{Ce}$ & $\mathrm{Pr}$ & $\mathrm{Nd}$ & Pm & Sm & Eu & Gd & $\mathrm{Tb}$ & Dy & Ho & Er & $\mathrm{Tm}$ & Yb & Lu & $\mathrm{H}$ & $T$ & & & Os & Ir & $\mathrm{Pt}$ & $\mathrm{Au}$ & $\mathrm{Hg}$ & $\mathrm{Tl}$ & $\mathbf{P b}$ & $\mathbf{B i}$ & Po & At & $\mathrm{Rn}$ \\
\hline $\mathrm{Fr}$ & $\mathbf{R a}$ & Ac & Th & $\mathrm{Pa}$ & U & $\mathrm{Np}$ & $\mathrm{Pu}$ & $\mathbf{A m}$ & $\mathrm{Cm}$ & Bk & Cf & Es & $\mathrm{Fm}$ & Md & No & $\mathbf{L r}$ & $\mathbf{R}$ & & & & Hs & $\mathrm{Mt}$ & Ds & Rg & Cn & $\mathbf{N h}$ & Fl & $\mathrm{Mc}$ & Lv & Ts & Og \\
\hline
\end{tabular}

(b)

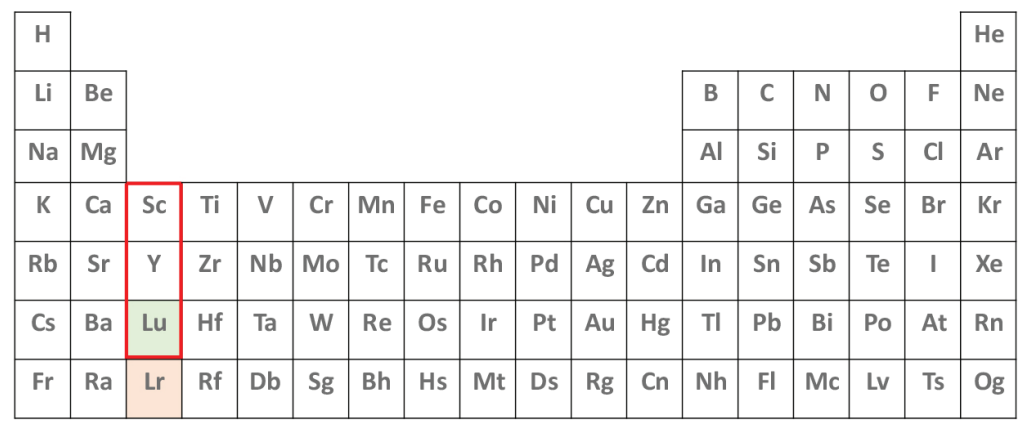

\begin{tabular}{|c|c|c|c|c|c|c|c|c|c|c|c|c|c|c|}
\hline Lantanídeos & La & $\mathrm{Ce}$ & $\mathrm{Pr}$ & Nd & Pm & Sm & $\mathrm{Eu}$ & Gd & Tb & Dy & Ho & Er & $\mathrm{Tm}$ & $\mathrm{Yb}$ \\
\hline Actiní & Ac & Th & $\mathrm{Pa}$ & U & Np & $\mathrm{Pu}$ & Am & $\mathrm{Cm}$ & Bk & Cf & Es & $\mathrm{Fm}$ & Md & No \\
\hline
\end{tabular}

Figura 9. Arranjo atual da Tabela Periódica (com destaque em vermelho para as TR), com a disposição sugerida para os lantanídeos (verde) e actinídeos (laranja) em formato (a) alongado (posicionando o bloco f como um intergrupo) e (b) condensado (representando o Grupo 3 como Sc-Y-Lu-Lr e com os elementos do bloco fem separado) 
massa de óxidos de TR, sendo $40-50 \% \mathrm{CeO}_{2}, 20-30 \% \mathrm{La}_{2} \mathrm{O}_{3}$, além de quantidades variáveis de traços $(<0,2 \%)$ a até $\sim 5 \%$ de $\mathrm{Y}_{2} \mathrm{O}_{3}$. A Tabela 1 mostra a composição média da monazita brasileira, que ocorre predominantemente na forma de areias, contendo quantidades variáveis de minerais acessórios como rutilo $\left(\mathrm{TiO}_{2}\right)$, ilmenita $\left((\mathrm{Fe}, \mathrm{Mn}, \mathrm{Mg}) \mathrm{TiO}_{3}\right) \mathrm{e}$ zirconita $\left((\mathrm{Zr}, \mathrm{TR}) \mathrm{SiO}_{4}\right)$. Como mostram os dados, o tório ocorre em porcentagens de $5 \%$, sendo que quantidades nem sempre pequenas de urânio também são presentes.

Tabela 1. Composição média (percentuais em massa) da monazita da costa brasileira ((Ce,La,Nd,Th) $\left.\mathrm{PO}_{4}\right)$ em termos de óxidos de TR e demais componentes $5,16,51$

\begin{tabular}{cccc}
\hline \multicolumn{2}{c}{ Composição Global } & \multicolumn{2}{c}{$\begin{array}{c}\text { Composição Relativa em } \\
\text { termos de TR }\end{array}$} \\
\hline Componente & $\begin{array}{c}\text { Percentual em } \\
\text { massa }\end{array}$ & $\mathrm{TR}_{2} \mathrm{O}_{3}$ & $\begin{array}{c}\text { Percentual em } \\
\text { massa }\end{array}$ \\
\hline $\mathrm{TR}_{2} \mathrm{O}_{3}$ & $57-62$ & $\mathrm{La}_{2} \mathrm{O}_{3}$ & 24,00 \\
$\mathrm{P}_{2} \mathrm{O}_{5}$ & $26-28$ & $\mathrm{CeO}_{2}$ & 47,00 \\
$\mathrm{ThO}_{2}$ & $5,0-6,0$ & $\mathrm{Pr}_{6} \mathrm{O}_{11}$ & 4,50 \\
$\mathrm{U}_{3} \mathrm{O}_{8}$ & $0,2-0,3$ & $\mathrm{Nd}_{2} \mathrm{O}_{3}$ & 18,50 \\
$\mathrm{ZrO}_{2}$ & $0,2-0,5$ & $\mathrm{Sm}_{2} \mathrm{O}_{3}$ & 3,00 \\
$\mathrm{TiO}_{2}$ & $0,2-0,5$ & $\mathrm{Eu}_{2} \mathrm{O}_{3}$ & 0,055 \\
$\mathrm{Fe}_{2} \mathrm{O}_{3}$ & $0,2-0,5$ & $\mathrm{Gd}_{2} \mathrm{O}_{3}$ & 1,00 \\
$\mathrm{Al}_{2} \mathrm{O}_{3}$ & $0,1-0,3$ & $\mathrm{~Tb}_{4} \mathrm{O}_{7}$ & 0,1 \\
$\mathrm{SiO}_{2}$ & $0,1-0,3$ & $\mathrm{Dy}_{2} \mathrm{O}_{3}$ & 0,35 \\
$\mathrm{CaO}^{2}$ & $0,3-0,8$ & $\mathrm{Ho}_{2} \mathrm{O}_{3}$ & 0,035 \\
- & - & $\mathrm{Er}_{2} \mathrm{O}_{3}$ & 0,07 \\
- & - & $\mathrm{Tm}_{2} \mathrm{O}_{3}$ & 0,005 \\
- & - & $\mathrm{Yb}_{2} \mathrm{O}_{3}$ & 0,02 \\
- & - & $\mathrm{Lu}_{2} \mathrm{O}_{3}$ & -- \\
- & - & $\mathrm{Y}_{2} \mathrm{O}_{3}$ & 1,4 \\
\hline
\end{tabular}

Desde as épocas em que as TR não possuíam aplicações específicas até os períodos em que sua aplicabilidade era bem estabelecida, a prospecção da monazita no Brasil sempre acabou por ser voltada à exploração do tório e do urânio nela presentes. O início da exploração das TR no Brasil se dá na década de 1880 com a retirada das areias de Prado, na Bahia. À época, as TR conhecidas tinham aplicações bastante limitadas, e o grande interesse na exploração do minério era o tório. Seu uso se concentrava principalmente na fabricação de mantas para lampiões a gás, que haviam sido recentemente desenvolvidas pelo austríaco Carl Auer von Welsbach (Figura 10). ${ }^{9,52}$ Discípulo de outro famoso químico, o alemão Robert Bunsen, Welsbach foi um importante cientista no período da separação das TR, contribuindo, tal como já mencionado, para o isolamento do praseodímio e do neodímio a partir do elemento então conhecido como "didímio", bem como pelo isolamento do "cassiopeio" (nome por ele dado ao lutécio, descoberto ao mesmo tempo por Georges Urbain). Durante sua permanência nos laboratórios de Bunsen, Welsbach constatou que óxidos de TR e tório emitiam uma luz brilhante ao serem mantidos na chama de queimadores a gás. Em 1885, Welsbach depositou a patente da chamada "lâmpada de Auer", em que tecidos de algodão embebidos em nitrato ou acetato de tório produziam, após tratamento apropriado com vapor de amônia, uma fina e delicada camada de óxidos que intensificava através de sua incandescência a luminosidade de chamas provenientes da queima de gases. ${ }^{9}$

Além de químico extremamente habilidoso, Welsbach era um entusiasta do desenvolvimento das aplicações das TR, pois durante

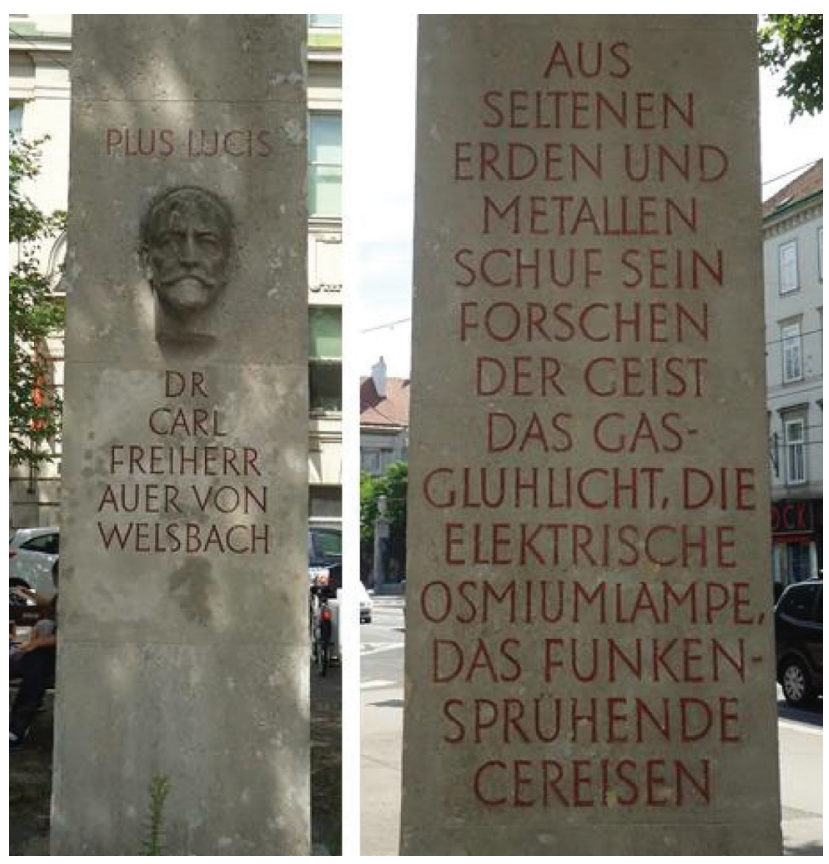

Figura 10. Busto em homenagem a Carl Auer von Welsbach nas proximidades do Instituto de Química da Universidade de Viena (Áustria), em virtude de suas contribuições à iluminação através "de pesquisas com cério e metais para a criação de lâmpadas a gás, lâmpadas elétricas de ósmio e do mischmetal utilizado em pedras para isqueiros"

muitos anos buscou por aplicações ao excedente de TR decorrente da extração do tório da monazita para a fabricação das mantas de lampião. Assim, surgiram as constatações de que a adição de cério às soluções de nitrato/acetato de tório levava ao aprimoramento das mantas para lampiões e aumento da luminosidade, no que consistiu na primeira aplicação comercial das TR. Paralelamente, Welsbach também conduziu à utilização do "mischmetal" (também chamado de Cereisen ou Auermetall em alemão, liga metélica contendo $50 \%$ de $\mathrm{Ce}, 25 \%$ de La e diferentes quantidades de Pr e Nd, além de Fe e Mg) na produção de pedras para isqueiros. Essas foram as duas principais aplicações das TR até meados da década de $1950{ }^{1}$

A empresa fundada por Welsbach, a Treibacher Industrie AG, que ainda atualmente mantém seu nome e o envolvimento no setor das TR, chegou, em 1913, a produzir 300.000.000 peças das mantas para lampiões recentemente desenvolvidas, utilizando tório e TR provenientes de 3000 ton de areia monazítica brasileira. ${ }^{9}$ Os primeiros registros da exploração de monazita no Brasil datam de 1884, quando a empresa exportadora E. Johnston \& Co. tem contato com as areias densas de algumas praias do Espírito Santo e da Bahia: ${ }^{53,54}$

"Veleiro de Ed. Johnston \& Company aporta em fins de 1884, em Caravelas, Bahia, para carregar madeira. Um dos marinheiros aproveita a folg a para percorrer a pitoresca praia que se estende da Ponta da Baleia até Prado, e observa no sopé das barreiras, manchas de areias pretas e outras intensamente amarelas. Enche uma garrafa com a areia dourada e embarca, em São Mateus, para o Rio de Janeiro; procura o cônsul britânico e mostra-lhe o achado: 'se não é ouro, deve conter outro metal precioso, pois é brilhante e denso!'. Nada entendendo de minérios, o agente consular prontifica-se a pô-lo em contato com John Gordon. Conquanto diplomado em engenharia de minas pela Universidade de Louisiana, este confessa-se incapaz de identificar o estranho minério. Leva-o ao Museu Nacional, onde O. A. Derby suspeita à primeira vista que se trata da rara monazita, recém-descrita por 
Gorceix como satélite do diamante no Salobro, município de Canavieiras, e não incluída entre os minerais industriais"... "Dotado espírito prático, Gordon procura aplicação para esse fosfato de terras céricas e tório. Informado de que Auer von Welsbach acaba de patentear o emprego de terras raras em camisas incandescentes de iluminação a gás (1885), oferece o minério brasileiro a essa indústria. Recebe pedido de amostra para ensaios industriais e embarca por intermédio da casa Williams, do Salvador, 300 toneladas de areia monazítica, como lastro de navio, para Hamburgo. E enquanto aguarda o resultado das pesquisas que custeia, requer o aforamento de uma légua de praia no Prado, onde localiza as concentrações maiores".

Note-se, portanto, que a exploração da monazita inicia-se em 1885 de maneira ilegal, sendo que os navios que chegavam ao país com produtos da Europa e da América do Norte eram, na ocasião de seu retorno, preenchidos com as areias monazíticas com o pretexto de ser usada como lastro, uma vez que os navios não poderiam voltar vazios. Essa retirada gratuita perdura até 1890, quando os governos locais suspendem a exportação irregular de monazita, estimando-se que, durante esses cinco anos, milhares de toneladas ( 15000 ton) tenham sido irregularmente embarcadas à Europa. ${ }^{1,55}$ Por exemplo, registra-se que, apenas no ano de 1898, 2338 sacas e 220 barris de monazita foram embarcados do Brasil com destino ao porto de Hamburgo, enquanto 1300 sacas foram embarcadas com direção a Southampton; cada barril equivale a duas sacas, e uma saca tem massa de $\sim 45 \mathrm{~kg}$ (100 pounds). ${ }^{55} \mathrm{O}$ artífice dessa exploração foi, conforme mencionado, o engenheiro John Gordon através da firma E. Johnston \& Co.. Cidadão americano radicado no Rio de Janeiro, Gordon manteve na Europa fama de contrabandista pelo fato de iniciar de maneira ilegal as exportações (que na verdade eram simples transferências de volumes) ao porto de Hamburgo. ${ }^{53}$

Nos anos seguintes, Gordon obtém junto aos proprietários das terras e aos governos federal e locais o aforamento dos terrenos, isso é, a concessão de privilégios para a exploração de todas e quaisquer areias contidas ao longo da costa nas delimitações estipuladas (em aproximadamente $33 \mathrm{~m}$ de praia a contar do ponto médio entre as marés baixa e alta). ${ }^{55,56}$ Contudo, os preços estipulados para a retirada "legal" das areias monazíticas eram essencialmente baixos, que em nada contribuíam com a economia brasileira, embora fossem extremamente rentáveis aos exploradores com a venda às empresas europeias. Por exemplo, relata-se que apenas a Empresa de Iluminação Incandescente de Viena, concessionária das patentes de Welsbach, teria adquirido, até 1897, em torno de 1300 toneladas da monazita de Prado, pagando por esse volume o valor de 750000 francos, equivalentes a 900 contos de réis, a J. Gordon. ${ }^{57}$ Por outro lado, a areia monazítica deixava as praias brasileiras por menos de 10 dólares por tonelada, enquanto mencionam-se, por exemplo, ocasiões em que a tonelada da monazita baiana era "vendida" pela quantia de 0,18 centavos de libra, o que correspondia a menos de um dólar da época. ${ }^{58,59}$ Convertendo-se em valores atuais, pode-se considerar que tonelada da monazita era vendida pela quantia de aproximadamente 25-30 reais brasileiros atuais. Em 1899, relata-se que J. Gordon possuía o direito exclusivo de exploração da monazita de Prado, considerada durante aquele período o maior e mais rico depósito já descoberto desse mineral..$^{55}$ À época da exploração das praias brasileiras no fim do século XIX e início do século XX, a economia brasileira era majoritariamente baseada na exportação do café e de outros produtos agrícolas, como o tabaco, por exemplo. ${ }^{57,58}$ Contudo, o fato de que a monazita não era tratada como um recurso de primeira grandeza a ser explorado na economia brasileira não é propriamente relacionado ao desconhecimento das aplicações dos elementos nela presentes. Relata-se, por exemplo, que vários recursos minerais do Brasil foram ressaltados já na Exposição Universal de Saint-Louis em 1904 através de relatórios dos comissariados brasileiros. ${ }^{53} \mathrm{Na}$ ocasião, destacavam-se a natureza dos depósitos brasileiros de monazita, bem como as aplicações industriais dos seus recursos, traçando-se comparações com os depósitos americanos.

No início da década de 1900, havia 66 companhias de mineração inglesas possuindo propriedades no Brasil, com um capital estimado em 8.000.000 de libras. Já em 1911, era sabido que os depósitos de monazita se estendiam da Bahia ao norte do Rio de Janeiro, com presenças eventuais no Estado de Minas Gerais, de modo que as concessões governamentais concentravam a exploração dos recursos em duas empresas, o que à época já era considerado um monopólio. Nesse período, já se empregavam plantas de separação nas proximidades do Rio Paraíba do Sul, no Estado do Rio de Janeiro, consistindo em separadores de Wilfley para a separação da sílica comum, bem como separadores de Humboldt para a separação dos componentes magnéticos. A aplicação desses processos permitia a concentração dos minerais para o aumento do valor relacionado à sua venda $\mathrm{e}$ transporte, sendo que pesquisadores alemães já estimavam que a quantidade de compostos radioativos na monazita brasileira poderia quadruplicar o valor a ela associado. ${ }^{53-58}$

Observa-se, assim, que o Brasil possuía um papel central no emergente mercado das TR. Contudo, a partir da década de 1910, o Brasil deixa de ser o núcleo do comércio mundial de monazita, uma vez que se descobrem outros importantes depósitos ao redor do mundo, como, por exemplo, na Índia, Sri Lanka, África do Sul e Austrália. Já em 1914, o Brasil perde o posto de maior fornecedor mundial de monazita para a Índia (Figura 11). Em 1917, investidores já previam a quebra do domínio brasileiro-alemão nos papéis de fornecedor-produtor com relação à manufatura de mantas de lampião a gás, no caso do Brasil devido à descoberta de novos depósitos de monazita e, no caso da Alemanha, devido ao iminente fim da $1^{\text {a }}$ Guerra Mundial e eventual quebra de patentes. ${ }^{60-62}$ Contudo, a partir do início da década de 1920, observa-se um declínio geral na produção de monazita, o que não foi um evento particular ao Brasil.$^{63}$ Nesse caso, a diminuição dos volumes de monazita movimentados ao redor do globo é diretamente relacionada ao advento da iluminação elétrica, ${ }^{9}$ que diminuiu drasticamente a demanda pelas mantas incandescentes de lampiões a gás. A então nova tecnologia, também desenvolvida em sua grande parte pelo mesmo Carl Auer von Welsbach, empregava principalmente metais como ósmio e, posteriormente, tungstênio, levando à redução da demanda industrial por tório e TR. ${ }^{9,52}$

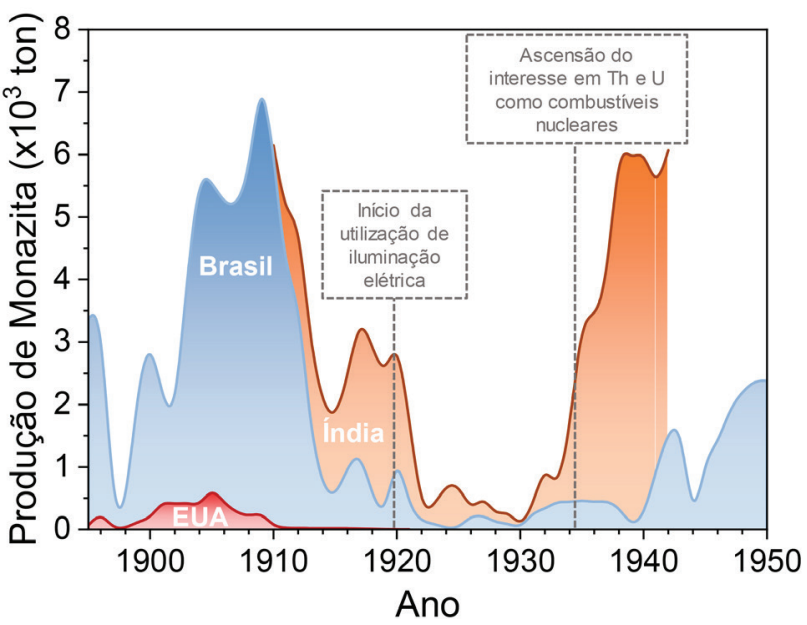

Figura 11. Evolução da produção de monazita entre o fim do século XIX e a primeira metade do século XX, ilustrando as frações correspondentes à contribuição de Brasil, EUA e Índia (construído a partir de dados da literatura) ${ }^{63}$ 
O declínio do interesse dos exploradores internacionais foi, como de praxe na história brasileira, acompanhado pela perda do já fraco envolvimento governamental na exploração dos recursos, de modo que, nas décadas subsequentes, coube basicamente à iniciativa privada a exploração e separação da monazita.

O ressurgimento da exploração de monazita no Brasil e em outros países detentores de depósitos se dá em meados da década de 1930, devido crescente interesse com relação ao tório e ao urânio presentes nesse mineral em meio à iminência da $2^{\mathrm{a}}$ Guerra Mundial (Figura 11). De fato, com a ascensão do Projeto Manhattan na década de 1940, a disponibilidade de tório, urânio e TR volta a ser um tema estratégico às potências mundiais, o que reacende o mercado de exploração de monazita, tanto para o Brasil, como para os países contendo depósitos.

Mesmo nessa época, a fatia correspondente à contribuição da monazita às exportações brasileiras era consideravelmente baixa com relação aos tradicionais produtos agrícolas. Ainda assim, o Brasil ainda manteve, como mencionado na seção seguinte, um importante papel no fornecimento de TR purificadas até a década de 1960, enquanto a produção de TR foi limitada principalmente pela disponibilidade de depósitos de areias aluviais, tal como a monazita brasileira (Figura 12). ${ }^{64}$ A partir da década de 1960, a produção de TR passou a ser dominada pelos Estados Unidos, com a exploração das reservas, principalmente de bastnasita, em Montain Pass. O domínio americano durou até meados da década de 1990, quando a China passou a figurar no cenário internacional como o mais importante detentor e produtor de TR. A entrada da China no campo das TR acabou por catalisar a diminuição das atividades dos principais processadores mundiais. Em 1992, o líder político chinês Deng Xiaoping afirmou, com exímia visão sobre o futuro de seu país, que se "o Oriente médio tem petróleo, a China tem metais raros". Com efeito, o domínio chinês sobre as TR iniciou-se, de fato, nesse período.

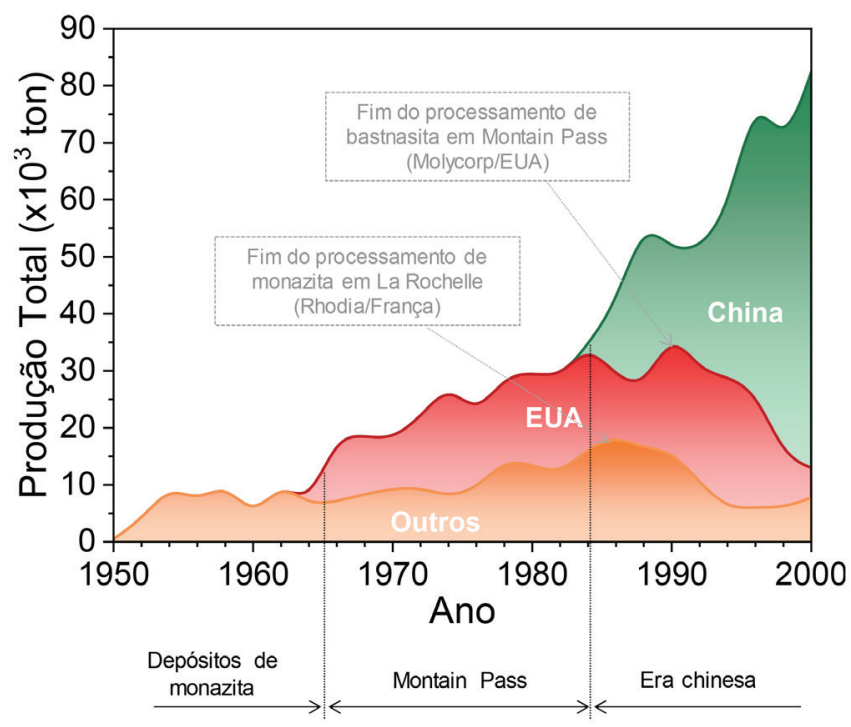

Figura 12. Evolução da produção mundial de TR (em toneladas de óxidos) durante a segunda metade do século XX e participação relativa de seus principais fornecedores. (Adaptado da literatura) ${ }^{64}$

\section{A ORQUIMA E AS TERRAS RARAS NO BRASIL}

Excetuando-se a venda ou entrega de monazita às mineradoras estrangeiras, as primeiras atividades concretas de exploração das TR em solo brasileiro podem ser atribuídas aos trabalhos de Pawel Krumholz ${ }^{65,66}$ na década de 1940 na ORQUIMA, instalada na cidade de São Paulo. Antigo assistente de Fritz Feigl, um dos mais importantes nomes da Química Analítica Qualitativa do século XX,
Krumholz era um habilidoso químico de origem polonesa. São da autoria de Krumholz os mais antigos trabalhos indexados desenvolvidos no Brasil sobre as TR que, após pesquisas realizadas nos laboratórios da ORQUIMA ou em sua própria residência, versavam sobre a instrumentação, ${ }^{67,68}$ a espectroscopia de compostos de $\mathrm{Nd}^{3+},{ }^{69,70} \mathrm{e}$ sobre a separação de TR e tório provenientes da monazita através de técnicas de troca iônica. ${ }^{71}$ Com a evolução dos trabalhos em escala laboratorial e grande ênfase em pesquisa, desenvolvimento e capacitação de recursos humanos, a ORQUIMA passou a produzir TR em escala industrial a partir de 1948. As instalações, que à época situavam-se em uma região então pouco povoada e distante do centro de São Paulo (Av. Santo Amaro), possuíam capacidade suficiente de processamento para a produção de 2000 ton/ano de cloretos de terras raras $\left(\mathrm{TRCl}_{3}\right)$, embora os principais produtos de interesse nacional fossem o tório, o urânio e o fosfato de sódio. Os cloretos de TR obtidos podiam ser considerados, até certo ponto, como subprodutos do processamento da monazita, pois os concentrados finais de TR simplesmente não possuíam comercialização no Brasil e eram, portanto, exportados em sua grande parte. ${ }^{5}$ Durante esse período, a ORQUIMA dominou as todas as etapas de processamento da monazita (Figura 13), o que culminou em uma grande capacidade de produção de TR. A monazita (assim como a xenotima, outro mineral composto por fosfatos de TR) normalmente ocorre como mineral acessório junto a ilmenita (um titanato de ferro, $\mathrm{FeTiO}_{3}$, utilizado como abrasivo), ao rutilo (dióxido de titânio, $\mathrm{TiO}_{2}$, empregado em pigmentos e soldas) e à zirconita (ou zircão, um silicato de zircônio, $\mathrm{ZrSiO}_{4}$, aplicado em cerâmicas), de modo que seu tratamento para a recuperação de TR envolve, inicialmente separação física desses outros minerais. ${ }^{1,7}$ Essas separações físicas compreendem métodos gravitacionais e eletromagnéticos, de modo que se obtenha uma monazita pré-concentrada para o tratamento. A monazita pré-concentrada é então tratada com ácido sulfúrico concentrado em altas temperaturas $\left(200-220^{\circ} \mathrm{C}\right.$ ) (Figura 13a) ou com soda cáustica, seja por fusão alcalina a $400{ }^{\circ} \mathrm{C}$, seja por tratamento hidrotermal a $150{ }^{\circ} \mathrm{C}$, o que em ambos os casos é seguido por dissolução com $\mathrm{HCl} 30 \%$ a $70{ }^{\circ} \mathrm{C}$ (Figura 13b). Esse último processo, conhecido como abertura alcalina, foi o mais frequentemente empregado pela ORQUIMA para o processamento da monazita.

Além de dominar as etapas de processamento da monazita, a ORQUIMA, com Krumholz e seus colaboradores, também foi pioneira no Brasil no que tange à separação dos concentrados de TR em elementos individuais, o que pode ser, sem dúvida, apontado como a etapa mais complexa na cadeia relacionada à obtenção desses elementos. Os principais métodos clássicos de separação de TR aplicáveis em grandes escalas envolvem as cristalizações fracionadas (com nitratos duplos de amônio ou sulfatos duplos de sódio) e processos que envolvem alteração no estado de oxidação (separação de cério por oxidação $\mathrm{Ce}^{3+} / \mathrm{Ce}^{4+}$ ou de európio por redução $\left.\mathrm{Eu}^{3+} / \mathrm{Eu}^{2+}\right)$. $^{1,5,7,16}$ As técnicas cromatográficas desenvolvidas na década de 1940 foram as primeiras capazes de promover uma separação efetiva de TR para compostos de elevada pureza $(>99,9 \%)$ em tempo e escalas industrialmente aceitáveis, compreendendo processos de troca iônica, cromatografia de deslocamento e troca líquido- líquido. Contudo, atualmente, os métodos mais empregados para a separação de TR consistem em extrações com solventes coordenantes (como ácido 2-etil-hexilfosfórico, tributilfosfato ou aminas de cadeia longa)., ${ }^{2,16}$ A ORQUIMA, por sua vez, realizava principalmente separações de TR por processos de mudanças de valência, cristalizações fracionadas e troca iônica. Com a aplicação dessas técnicas, a ORQUIMA tornou-se o principal produtor mundial de óxido de európio $\left(\mathrm{Eu}_{2} \mathrm{O}_{3}\right)$ de alta pureza entre as décadas de 1940-1950, produzindo centenas de quilos. ${ }^{5}$ Em 1961, um dos autores (OAS) supervisionado por Krumholz isolou, por troca iônica, $18 \mathrm{~g} \mathrm{de} \mathrm{Lu}_{2} \mathrm{O}_{3}$, a maior quantidade 


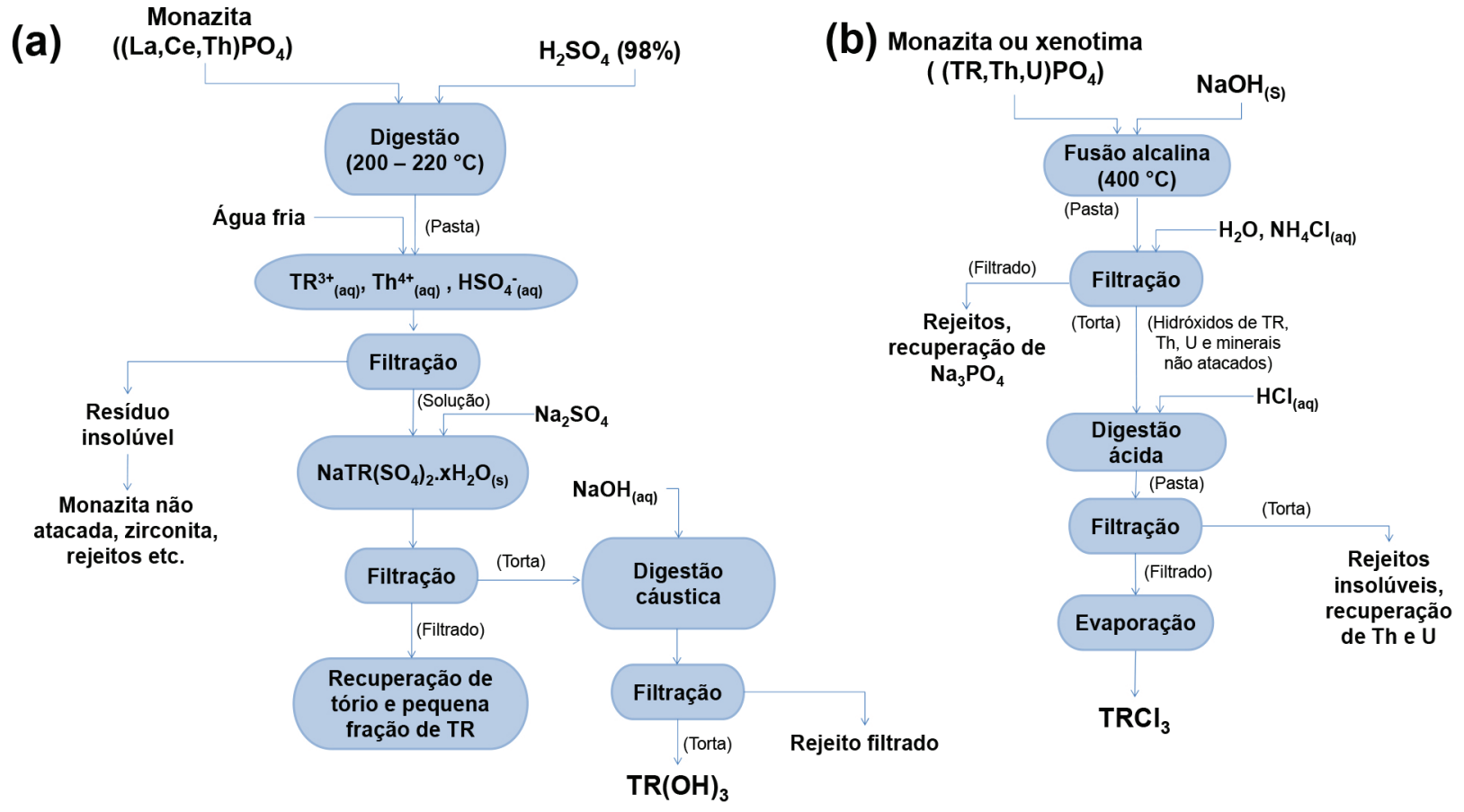

Figura 13. Esquematização das metodologias de processamento da monazita e xenotima através (a) de abertura ácida por ataque com ácido sulfúrico e (b) abertura alcalina utilizando-se soda cáustica (Reproduzido da Ref. 1)

desse composto até então conhecida. A empresa chegou a fornecer, por exemplo, $\mathrm{Eu}_{2} \mathrm{O}_{3}$ de alta pureza para a fabricação das barras de európio metálico utilizadas em sistemas de contenção de nêutrons, empregados na construção do primeiro submarino nuclear operacional do mundo, o Nautilus (1955). ${ }^{36}$

Entretanto, foi justamente a intensificação do interesse, tanto brasileiro como internacional, nas tecnologias de energia nuclear que acabou por interromper a evolução da ORQUIMA nas técnicas de processamento/separação de TR e a provável consolidação do Brasil no cenário mundial como detentor das tecnologias para a produção de TR de alta pureza. A abundância de tório e urânio na monazita brasileira despertou, na década de 1950, o interesse governamental para a utilização desses metais como combustíveis nucleares. De fato, o Brasil possui uma das maiores reservas de recursos nucleares, contando com uma das maiores quantias naturais de tório e o sexto maior volume de minérios de urânio (309.000 ton em $\mathrm{U}_{3} \mathrm{O}_{8}$ ) do planeta. ${ }^{72} \mathrm{~A}$ ausência de um programa de utilização desses recursos seria certamente incompatível com propostas de desenvolvimento do país. Assim, nesse período, a legislação brasileira passou a tratar como responsabilidade governamental o processamento de minerais contendo potenciais materiais e combustíveis nucleares, sobretudo tório e urânio. Dessa forma, o processamento da monazita passou a ser responsabilidade da Comissão Nacional de Energia Nuclear (CNEN), que adquiriu as instalações da ORQUIMA, posteriormente nomeada APM (Administração da Produção de Monazita). ${ }^{5}$ A transferência completa das instalações da ORQUIMA ao governo conclui-se em 1966, sendo que a APM tinha como objetivo a produção de urânio e tório como combustíveis nucleares, sendo a produção e venda dos outros produtos do tratamento da monazita (TR e fosfatos), tratada como atividade secundária. Com isso, poucos esforços continuaram destinados ao fracionamento das TR individuais, sendo que a APM comercializava apenas concentrados de cloretos TR ou óxidos de TR de baixa pureza (mistura de todas as TR presentes na monazita tratada), embora na década de 1970 a empresa fornecesse concentrados enriquecidos em determinadas TR (cério, lantânio e "didímio", mistura de praseodímio e neodímio). ${ }^{5}$
Em 1972, criou-se a Companhia Brasileira de Tecnologia Nuclear (CBTN), novo órgão responsável pelas ações relacionadas às TR, tório e urânio que, portanto, passou a gerir a APM, cujas atividades de processamento da monazita em São Paulo continuaram até 1974. Em 1976, a CBTN passou a ser denominada NUCLEBRÁS (Empresas Nucleares Brasileiras S. A.), absorvendo as instalações da APM, que passaria a ser chamada Nuclebrás de Monazita e Associados Ltda. Essa mudança novamente não alterou o fato de que pouco ou nenhum avanço era realizado no Brasil em termos de separação e aproveitamento dos recursos de TR, sendo que, em 1988, a NUCLEBRÁs passou a ser denominada como INB (Indústrias Nucleares do Brasil S. A.), convertendo a Nuclebrás de Monazita em NUCLEMON Mínero-Química Ltda.. ${ }^{5,51}$

Nesse período de mais de vinte anos, a exploração das TR oriundas da monazita brasileira passou ao controle governamental e, após sucessivas mudanças de denominação, os avanços esperados pelo papel de destaque que o país outrora ocupou no cenário mundial das TR jamais chegariam. Entre a década de 1960 e o fim da década de 1980, a ex-ORQUIMA/APM/ Nuclebrás de Monazita/NUCLEMON passou por poucos avanços tecnológicos graças aos raros e esparsos investimentos. As atividades de pesquisa e desenvolvimento, que no período inicial, eram o cerne do pioneirismo da ORQUIMA, foram completamente estagnadas, com baixa taxa de formação, atualização e treinamento de mão-de-obra capacitada na área. A estatização foi seguida por anos de obsoletização. Note-se que, praticamente nesse mesmo período ( 1960-1980), o mundo via as TR começarem a ser aplicadas nos primeiros televisores a cores (1954, utilizando compostos de ítrio e európio), nos primeiros lasers funcionais (1960, com compostos de ítrio, érbio e neodímio), e nos primeiros ímãs permanentes de alta capacidade (1982, ligas de neodímio-ferro-boro), por exemplo. Frente a esse cenário, no mesmo período em que o Brasil obsoletizava sua até então promissora produção de TR, países como EUA e Austrália investiam em novas técnicas de prospecção e tratamento de seus recursos, enquanto a China acelerava cada vez mais as atividades de pesquisa e desenvolvimento em relação à exploração desses elementos. Como resultado, quando esses elementos 
começaram a ganhar maiores valores agregados nos anos 1970 e 1980, especialmente com luminóforos e magnetos, o Brasil já não possuía qualquer competitividade no setor.

Dessa forma, todo o investimento tecnológico e em recursos humanos na área de processamento de minérios e separação de TR foi praticamente perdido e, na década de 1990, a NUCLEMON comercializava apenas fosfato de sódio, cloretos, fluoretos, carbonatos, óxidos e hidróxidos mistos de TR, além de alguns concentrados de pureza baixa ou intermediária (85-98\%). ${ }^{5}$ Em 1992, a NUCLEMON encerrou suas atividades industriais em São Paulo, mas continuou a produzir baixas quantidades TR até 1994, quando foi extinta, tendo suas atividades diretamente transferidas à INB. Embora tenha havido várias tentativas de contratos (com o Instituto de Engenharia Nuclear, por exemplo) para o desenvolvimento de processos de obtenção de TR individuais de alta pureza por extração com solventes, as atividades foram progressivamente reduzidas até que, entre 2002 e 2005 , praticamente encerrou-se a produção de TR no Brasil. ${ }^{51}$

\section{AS TR NO BRASIL PÓS-2009}

No início da década de 1990, a produção de TR no mundo era de aproximadamente 50000 ton, sendo que a China correspondia a uma produção de menos de $50 \%$ desse valor (Figura 12). A diminuição dos custos de produção e o aumento das restrições ambientais em países como EUA, Austrália e Canadá levaram à diminuição da produção nesses países, conduzindo a um domínio chinês no mercado das TR. Em 2009, a China era responsável pela venda de mais de $97 \%$ dos compostos de TR ao redor do globo. Nesse mesmo ano, devido ao aumento da demanda interna chinesa para a manufatura de produtos finais (turbinas eólicas, baterias e luminóforos) e à maior rigidez quanto à regulação ambiental, a China chegou a aumentar em dez vezes o preço das TR comercializadas, com o estabelecimento de quotas de exportação. ${ }^{1,36}$ Essa ação causou um grande impacto nos principais consumidores de TR (EUA e Japão) e em outros países, que iniciaram suas mobilizações para a retomada de suas produções de TR além de buscarem acordos comerciais.

No Brasil, a percepção da vulnerabilidade econômica associada à ausência de TR levou também a uma mobilização, a partir de 2010, para o aproveitamento dos recursos nacionais através da criação de um Grupo de Trabalho Interministerial de Minerais Estratégicos dos (à época) ministérios de Minas e Energia (MME) e de Ciência e Tecnologia e Inovação (MCTI). Esse grupo de trabalho (Portaria Interministerial $\mathrm{N}^{\mathrm{o}} 614 / 2010$ de 30 de junho de 2010) culminou com a elaboração de diversos levantamentos geológicos e estudos da cadeia produtiva envolvendo as TR. Diversas localidades ao longo do território brasileiro têm imensa potencialidade para a produção de TR, devido ao enorme volume em minerais de alto teor desses elementos. ${ }^{73,74}$ Tais regiões compreendem, por exemplo, Pitinga (AM), Catalão (GO), Morro do Ferro (MG) e Rio Sapucaí (MG), que, em alguns casos, apresentam não apenas grande volume, mas também grande concentração das TR com maior valor agregado. Há, ainda, diversas outras localidades em que as TR podem associadas à prospecção de outros metais, podendo assumir o papel de subprodutos da exploração de $\mathrm{Sn}, \mathrm{Zr}$, Ta-Nb, Ti, Au e Fe, por exemplo. Ao todo, os recursos brasileiros em TR são estimados em mais de vinte milhões de toneladas, embora grande parte desse volume seja relativo a minerais com processamento ainda não estabelecido ou inviável ambiental ou economicamente. Além disso, desde 2010, o governo tem encontrado grande dificuldade em atrair investimentos ao setor da exploração das TR, uma vez que esses elementos correspondem a uma fatia muito pequena do mercado em comparação aos grandes volumes da mineração do ferro ou da prospecção do petróleo. ${ }^{1}$ Dessa forma, uma maior mobilização dos setores acadêmicos (em particular nas áreas de química, física, geologia e engenharia de minas) e dos setores empresariais por parte do governo é imprescindível para o aproveitamento adequado dos recursos brasileiros.

\section{APLICAÇÕES}

Materiais constituídos de TR são cruciais em muitas tecnologias modernas, como smartphones, televisores e monitores, discos rígidos, veículos híbridos e elétricos e muitos outros. A indústria de TR beneficia a economia em todo o mundo com sua extensa cadeia de fornecimento e aplicações. Suas propriedades magnéticas, ${ }^{2,3}$ catalíticas, ${ }^{27-29,75,76}$ e ópticas ${ }^{77}$ as tornam aplicáveis em diferentes e variados campos. ${ }^{78-80} \mathrm{Em}$ particular, suas propriedades luminescentes, conferidas pelas intensas e estreitas bandas de emissão, resultantes de transições do tipo $f-f$, geram cores específicas em dispositivos luminescentes. ${ }^{81,82}$ Assim, materiais luminescentes contendo terras raras possuem extensa aplicação em dispositivos de iluminação, como displays emissores e lâmpadas fluorescentes, ${ }^{83,84}$ sendo extensamente processados na forma de luminóforos de estado sólido, ${ }^{85-99}$ materiais híbridos e compostos de coordenação, ${ }^{100-108}$ vidros, ${ }^{109-114}$ híbridos magnéticos-luminescentes, ${ }^{115,116}$ entre muitos outros. Além disso, a utilização de ferramentas teóricas para a descrição da luminescência de lantanídeos é extremamente útil para o aprimoramento e adaptação das propriedades observadas. ${ }^{117-121} \mathrm{O}$ número crescente de aplicações industriais com elementos de terras raras despertou o interesse em novas tecnologias de extração via fontes alternativas. ${ }^{122-128}$

Embora as propriedades luminescentes dos compostos de TR fossem conhecidas desde o final do século XIX e início do século XIX, o primeiro composto usado contendo terras raras foi o vanadato de ítrio dopado com európio(III), emissor vermelho. ${ }^{9}$ No final da década de 1960, os fosfatos de estrôncio dopados com $\mathrm{Eu}^{2+}$ eram utilizados como emissores azuis. Os emissores verdes que utilizavam o íon térbio(III) surgiram na década de 1970, quando a Philips introduziu o primeiro sistema baseados nas três cores primárias, vermelho, verde e azul (RGB), contendo apenas compostos de TR, conforme ilustrado na Tabela 2. ${ }^{9,129}$

Tabela 2. Composição do primeiro sistema RGB contendo apenas $\mathrm{TR}^{9,129}$

\begin{tabular}{cccc}
\hline Cor & Matriz & Ativador & Emissão (nm) \\
\hline Azul & $\mathrm{BaMgAl}_{10} \mathrm{O}_{17}$ & $\mathrm{Eu}^{2+}$ & 450 \\
Verde & $\mathrm{CeMgAl}_{11} \mathrm{O}_{19}$ & $\mathrm{~Tb}^{3+}$ & 541 \\
Vermelho & $\mathrm{Y}_{2} \mathrm{O}_{3}$ & $\mathrm{Eu}^{3+}$ & 611 \\
\hline
\end{tabular}

Os halofosfatos, usados nos sistemas de emissão de luz, se mostraram menos eficientes com o tempo, devido a tendência global em diminuir o diâmetro dos tubos das lâmpadas. Com isso, os halofosfatos começaram a ser abandonados e os compostos de TR passaram a ser mais utilizados, com introdução das lâmpadas fluorescentes compactas, no início da década de 90. As lâmpadas tubulares são denominadas T12, T8, T5, T4, T2, em função de seus diâmetros, conforme a Tabela 3. Os materiais fosfóricos de lâmpadas recicladas contêm quantidades significativas de alumina $\left(\mathrm{Al}_{2} \mathrm{O}_{3}\right)$ e sílica $\left(\mathrm{SiO}_{2}\right)$ que são usadas como camada de barreira. A camada de barreira está presente entre a camada que contém material fosfórico e o tubo de vidro. Sua função principal é proteger o invólucro de vidro contra o ataque de vapor de mercúrio e, assim, evitar a perda de mercúrio da lâmpada e a redução da saída de luminosidade da lâmpada. A camada de barreira também melhora a eficiência da lâmpada, refletindo a luz UV que passa através da camada de material fosfórico para a camada de vidro. 
Tabela 3. Diâmetro das lâmpadas fluorescentes comerciais ${ }^{9}$

\begin{tabular}{ccc}
\hline Lâmpadas tubulares & Polegadas & Milímetros \\
\hline T12 & $12 / 8 "\left(11 / 2{ }^{\prime \prime}\right)$ & 38 \\
T8 & $8 / 8 "\left(1{ }^{\prime \prime}\right)$ & 26 \\
T5 & $5 / 8 ”$ & 16 \\
T4 & $4 / 8 ”$ & 12 \\
T2 & $2 / 8 ”$ & 7 \\
\hline
\end{tabular}

O principal fornecedor mundial de TR é a China, onde as TR estão amplamente disponíveis e são produzidas em grande escala (até $95 \%$ da demanda mundial). No entanto, a crescente demanda doméstica (mais de $70 \%$ de sua própria produção) depois que a China dominou as tecnologias para fabricar os produtos finais (turbinas eólicas, fósforos, baterias, ímãs etc.) juntamente com as várias restrições ambientais impostas, fizeram com que esse país aumentasse o preço médio das TR mais de dez vezes nos últimos anos. ${ }^{36,130,131}$ As restrições de fornecimento da China estão de encontro com o desenvolvimento de muitos novos projetos de mineração e recuperação, como o no caso o projeto RECOLA, que foi desenvolvido pela União Europeia em 2016 em colaboração com pesquisadores dos países: Argentina, Brasil, Peru, Itália e Polônia. ${ }^{132}$

O uso eficiente dos recursos naturais é mandatório em uma economia autossustentável. Isso só é possível pela reutilização e reciclagem de materiais provenientes de bens de consumo exauridos. ${ }^{133-135}$ Uma das formas mais promissoras de recuperar grandes quantidades de TR é usar resíduos de pó fosfórico de lâmpadas como fonte de TR; essas lâmpadas contêm alta concentração de TR (até 40\% dependendo do tipo de lâmpada). ${ }^{136,137}$ No final do ciclo de vida das lâmpadas fluorescentes, o mercúrio é removido e os resíduos são descartados em conjunto com os fósforos de TR. Por esse motivo, essas lâmpadas são consideradas fontes potenciais de TR, que podem ser obtidas através de processos de reciclagem. Nos últimos anos houve um aumento expressivo no número de trabalhos baseados em alternativas para recuperação de TR provenientes de resíduos de lâmpadas. Takahashi et al. recuperaram as TR em resíduos de pó fosfórico nas lâmpadas, utilizando processos baseados em gravidade, como separação pneumática junto com a lixiviação em ácido sulfúrico. ${ }^{138}$ Hiragima et al. trabalharam em um método baseado em centrifugação em meio denso, usando di-iodometano $\left(\mathrm{CH}_{2} \mathrm{I}_{2}\right) \cdot{ }^{139,140}$ No entanto, a baixa eficiência do primeiro método e os altos custos e efeitos ambientais negativos do meio denso orgânico utilizado no segundo processo levaram os pesquisadores a buscar uma tecnologia mais adequada.

Outra aplicação de extrema importância mundial são os catalisadores de craqueamento de petróleo (FCC), amplamente utilizados na indústria de petróleo e que geram quantidades significativas de resíduos com TR, como lantânio cério. O uso de zeólitas contendo TR em catalisadores de craqueamento foi descrito por Plank e Rosinski, ambos da Socony Mobil Oil, no início dos anos 60. Eles descobriram que as zeólitas contendo TR eram cerca de 100 vezes mais ativas do que os tradicionais catalisadores amorfos de sílica-alumina utilizados na época. Essa invenção teve um efeito mundialmente expressivo no processamento de petróleo. Plank e Rosinski foram introduzidos no Inventor Hall of Fame em 1979. ${ }^{141}$ Os FCCs são materiais usados no processamento de hidrocarbonetos, auxiliam na quebra (craqueamento) de grandes moléculas a partir de matérias-primas, como o gasóleo pesado (óleo mineral destilado do petróleo que fica entre o querosene e o óleo lubrificante). Embora sua constituição possa variar, eles são constituídos basicamente por aluminossilicatos microporosos cristalinos, também conhecidos como zeólitas, adicionadas a fim de aumentar o potencial do catalisador. Além disso, o zeólitas tem uma estrutura interna porosa com sítios ácidos que podem converter moléculas maiores em moléculas menores. Caulim, alumina e sílica são adicionados como complemento, Figura 14. Atualmente, os materiais catalíticos constituídos por terras raras desempenham um papel importante na indústria química do petróleo. ${ }^{142} \mathrm{O}$ catalisador de craqueamento, FCC, é indispensável para o refino de petróleo. Com o desenvolvimento do refino de petróleo, uma grande quantidade de catalisadores FCC vem sendo descartado em aterros sanitários; no entanto, a poluição ambiental do ar, do solo e do oceano contaminada por esses catalisadores de resíduos tornou-se um sério problema global. ${ }^{143}$

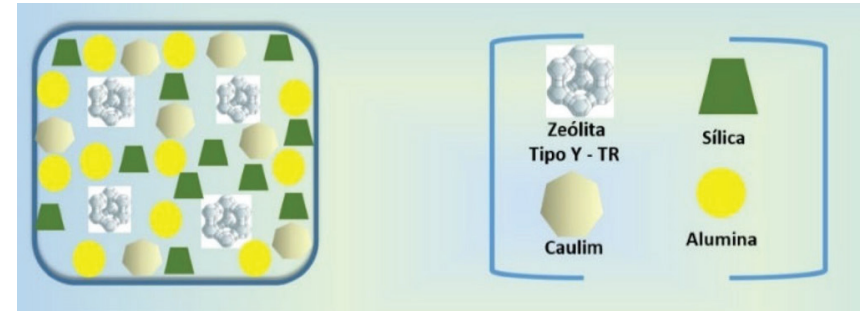

Figura 14. Ilustração da composição química e estrutural das partículas de FCC

Atualmente, uma nova classe de compostos, as redes metalorgânicas (MOFs, Metal Organic Frameworks), bem como polímeros de coordenação, tem sido um tema de extrema relevância e interesse devido a suas vastas aplicações. ${ }^{144-151} \mathrm{O}$ número de trabalhos publicados em revistas científicas nacionais e internacionais na área que envolve o desenvolvimento de novas MOFs tem crescido exponencialmente, como apresentado na Figura 15. Isso se deve à versatilidade dos materiais sintetizados a partir da vasta gama de metais e ligantes disponíveis. Desde os primeiros estudos de sensores luminescentes baseados em estruturas metalorgânicas contendo lantanídeos (LOFs, Lanthanoid Organic Frameworks) há cerca de dez anos, tem havido um interesse crescente no desenvolvimento de sensores específicos para cátions, ânions, explosivos, pequenas moléculas, solventes e pesticidas, por exemplo. A acessibilidade de várias "unidades de construção" de íons metálicos e ligantes orgânicos, permite a construção de estruturas fascinantes, novas topologias, e a manipulação direta de suas propriedades físicas e químicas. ${ }^{150}$

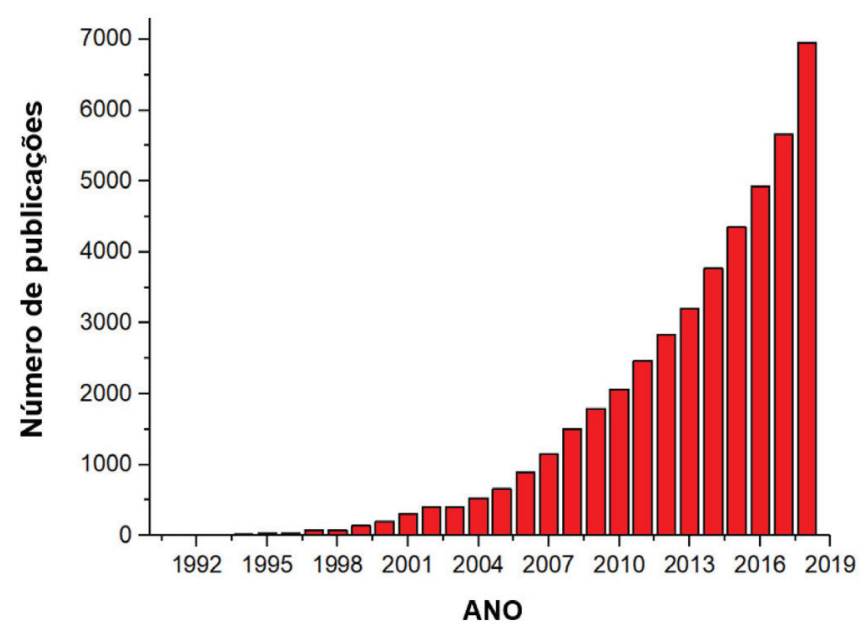

Figura 15. Número de publicações científicas com o termo "metal-organic frameworks or MOFs" presentes em "tópicos" até 2018. Construído a partir da ISI Web of Science

Mais e mais atenção tem sido dada ao design e síntese LOFs. Suas propriedades físico-químicas estão sendo investigadas profundamente, especialmente suas propriedades luminescentes. Os íons 
lantanídeos possuem vários níveis de energia oriundos das transições do tipo $f$ - $f$, o que pode produzir emissões que se expandem do ultravioleta (UV) ao visível (VIS) e infravermelho próximo (NIR). Complexos luminescentes exibem características únicas, como bandas de emissão estreitas oriundas das transições eletrônicas $4 f$, grandes separações entre máximos de excitação e de emissão (deslocamento pseudo-Stokes $>200 \mathrm{~nm}$ ) e longo tempo de vida de estado excitado, pouco afetados pelo ambiente químico. Sensores luminescentes usando LOFs representam um método simples, eficaz e confiável para reconhecer espécies. ${ }^{151} \mathrm{O}$ procedimento conhecido como modificação pós-sintética (PSM) oferece uma oportunidade para alterar e expandir suas propriedades. ${ }^{152}$

Com relação ao sensoriamento luminescente, a temperatura é um parâmetro termodinâmico fundamental, cuja medida é de interesse crucial em diversas investigações científicas e de desenvolvimento tecnológico. Em contraste com os sensores convencionais de temperatura (como termômetros de contato), o método baseado em luminescência é uma alternativa não-invasiva e com alta acurácia, devido sua rápida habilidade de resposta, alta resolução e alta resistência a campo magnético ou elétrico. Uma série de exemplos foram reportados por Chen, Cui et al., com misturas de lantanídeos, demonstrando comportamento especial de dependência entre temperatura e luminescência e suas potencias aplicações em termômetros luminescentes (Figura 16). ${ }^{153} \mathrm{Um}$ dos primeiros MOFs luminescentes sintetizados e utilizados como sensores termométricos foram as LOFs $\left[\mathrm{Tb}_{2}(\mathrm{DMBDC})_{3}\right]_{\mathrm{n}}$ e $\left[\mathrm{Eu}_{2}(\mathrm{DMBDC})_{3}\right]_{\mathrm{n}}$, em que DMBDC representa o ligante 2,5 dimetoxi-1,4-benzenodicarboxilato. Ambos exibiram luminescência característica quando excitados em $381 \mathrm{~nm}$, atribuída à transição eletrônica $\pi^{*} \leftarrow \pi$ do ligante, indicando que o ligante é um forte sensibilizador (cromóforo antena). Com o aumento de temperatura de 10 a $300 \mathrm{~K}$, a intensidade de luminescência de ambos MOFs, $\mathrm{Tb}^{3+} \mathrm{e} \mathrm{Eu}^{3+}$, diminui gradativamente devido à ativação térmica dos decaimentos não-radiativos. Diferentemente das LOFs que contém apenas um tipo de lantanídeo, nas redes mistas $\left(\mathrm{Tb}^{3+}{ }_{0.9931} \mathrm{Eu}^{3+}{ }_{0.0069}\right.$-DMBDC), o composto exibe uma interessante dependência entre luminescência e temperatura. A intensidade de emissão dos íons $\mathrm{Tb}^{3+}$ diminui, enquanto, para os íons $\mathrm{Eu}^{3+}$, aumenta com a temperatura. A diferente relação de dependência entre temperatura e o metal central na emissão, em um único composto, permite que o material seja um candidato ideal como referência em termômetros luminescentes, como virtualmente nenhuma calibração adicional de intensidade de luminescência é necessária. Nesse sentido, o campo da nanotermometria óptica utilizando a luminescência de íons lantanídeos é um campo em crescente ascensão, não apenas com a utilização de LOFs, mas também de nanopartículas sólidas e coloidais, com uma imensa gama de aplicações para o sensoriamento térmico em nanoescala. ${ }^{154-158}$

Além das aplicações como materiais luminescentes, as TR são fundamentais no campo dos materiais magnéticos. Atualmente, os magnetos de $\mathrm{Nd}_{2} \mathrm{Fe}_{14} \mathrm{~B}$ oferecem uma melhor relação potência-peso na indústria de ímãs e ainda mais alta eficiência na conversão de energia elétrica em energia mecânica em motores, ou vice-versa em geradores. Nos últimos anos, os dois mercados que mais cresceram para os magnetos $\mathrm{Nd}_{2} \mathrm{Fe}_{14} \mathrm{~B}$, foram os geradores de turbinas eólicas e dos motores de veículos elétricos. Entre outras, essas aplicações ilustram o papel e a importância das TR em novas tecnologias energéticas. Fabricantes líderes de grandes turbinas eólicas modernas, como a "Siemens Gamesa Renewable Energy" e a "MHI Vestas Offshore Wind", usam geradores de magnetos permanentes $\mathrm{Nd}_{2} \mathrm{Fe}_{14} \mathrm{~B}$ em suas avançadas turbinas eólicas também em alto mar (offshore). Para reduzir os custos de produção e melhorar o desempenho (particularmente para temperaturas mais altas), parte do neodímio (Nd) é substituído por outros elementos de terras raras, como praseodímio (Pr), disprósio (Dy) e térbio ( Tb). O teor total de elementos terras raras nos magnetos é tipicamente cerca de $32 \%$ em peso. ${ }^{159,160}$

Um dado de extrema relevância quando se pensa em energia sustentável é a quantidade de terras raras necessária para a geração de energia. Sabe-se que para a geração de $1 \mathrm{MW}$ de energia, nos geradores eólicos, são necessários $100 \mathrm{~kg}$ de $\mathrm{Nd}^{3+}$ para produção do dínamo (ou alternador). Para obtenção de $100 \mathrm{~kg}$ de $\mathrm{Nd}^{3+}$, são necessários $800 \mathrm{~kg}$ do minério monazita para extração. Como a monazita não se encontra pura na natureza, são necessários 8000 kg de minério bruto para sua extração e a utilização de aproximadamente $6000 \mathrm{~kg}$ de ácido sulfúrico concentrado. Por fim, o resíduo gerado nesse processo está em torno de $40 \mathrm{~kg}$ de material radioativo (tório proveniente da monazita) por MW de energia. Sendo assim, ainda que se pense em energia eólica ou em carros híbridos/elétricos como sustentáveis e limpos, há sempre de se considerar os danos causados ao meio ambiente para obtenção dos dínamos, necessários para o funcionamento desses importantes materiais.

\section{CONSIDERAÇÕES FINAIS}

O Brasil tem Terras Raras. Extraí-las e processá-las de modo sustentável é o desafio que se apresenta. No cenário mundial (inclusive Brasil) várias empresas promissoras e de competência nos

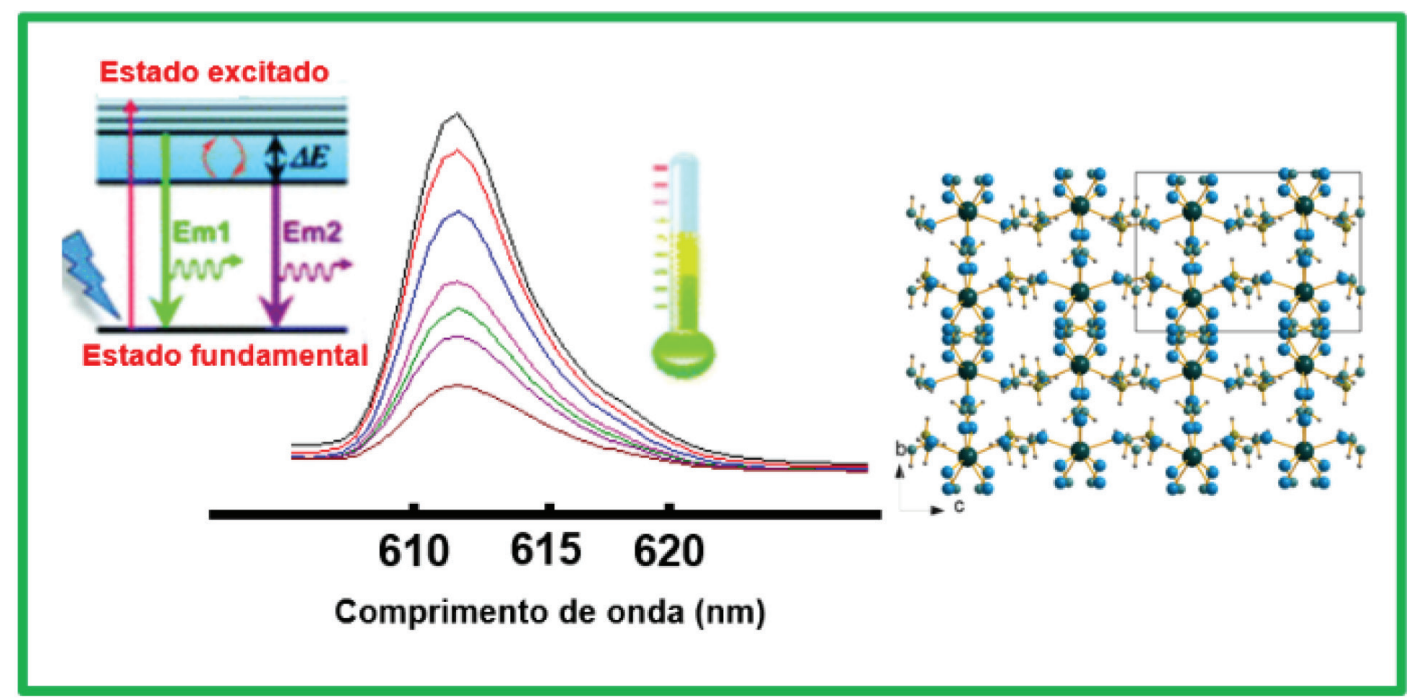

Figura 16. Ilustração do uso de LOFs como sensores térmicos luminescentes 
procedimentos foram à falência devido ao monopólio, controle de preços e fornecimento realizado pela China nos últimos anos. A China atraiu para o seu território as principais empresas usuárias de TR ao redor do mundo (USA, Alemanha, Japão), incentivando o seu desenvolvimento. O Brasil tem presença destacada nas publicações acadêmicas sobre as TR, a exemplo de outras áreas, mas as patentes são mínimas. A maioria dos países desenvolvidos possui uma relação aproximada de 5/1 de doutores em empresas/universidades, entre nós a relação é inversa. Há pouco incentivo à pesquisa e inovação nas empresas. Os alunos em sua maioria cursam universidades privadas, em que apenas o lucro imediato é visado e nas quais há pouco investimento em cursos técnicos e em pesquisa fundamental ou aplicada. $\mathrm{O}$ Brasil ocupa um papel chave no cenário mundial das TR. Não se pode permitir, via falta de investimentos e de planejamento estratégico, que as universidades e empresas brasileiras percam uma vez mais a possibilidade de construção e conexão com o futuro.

\section{AGRADECIMENTOS}

Os autores agradecem ao CNPq (Proc. 311312/2015-2, OAS e Proc. 141640/2016-2, ARBSG), à FAPESP (Proc. 2017/11764-2, PCdSF e Proc. 2018/07514-3, OAS) e à CAPES por bolsas e auxílios financeiros.

\section{REFERÊNCIAS}

1. de Sousa Filho, P. C.; Serra, O. A.; Quim. Nova 2014, 37, 753.

2. Sastri, V. R.; Bünzli, J.-C. G.; Rao, V. R.; Rayudu, G. V. S.; Perumareddi, J. R.; Modern Aspects of Rare Earth and their Complexes, Elsevier: Amsterdam, 2003.

3. Saez-Puche, R.; Caro, P. (Eds.); Rare Earths, Editorial Complutense: Madrid, 1998.

4. Cotton, S.; Lanthanide and Actinide Chemistry, Wiley: Chichester, 2006.

5. Abrão, A.; Química e Tecnologia das Terras-Raras, CETEM/CNPq: Rio de Janeiro, 1994.

6. Castor, S. B.; Hedrik, J. B. Em Industrial Minerals and Rocks: Commodities, Markets, and Uses; Kogel, J. E., Trivedi, N. C., Barker, M. J., eds.; Society for Mining, Metallurgy, and Exploration, Inc. (SME): Littleton, 2006, Cap. 58.

7. Zongsen, Y.; Mimbo, C.; Rare Earth Elements and their Applications, Metallurgical Industry Press: Beijing, 1995.

8. Connelly, N. G.; Damtus, T.; Hartshorn, R. M.; Hutton, A. T.; Nomenclature of Inorganic Chemistry - IUPAC Recommendations 2005, RSC Publishing: Cambridge, 2005.

9. Serra, O. A.; Lima, J. F.; de Sousa Filho, P. C.; Rev. Virtual Quim. 2015, $7,242$.

10. Hutton, A. T.; Connelly, N. G.; Hartshorn, R. M.; Damhus, T.; Nomenclatura de Química Inorgânica - Recomendações da IUPAC de 2005 (tradução da versão original em inglês produzida pela divisão de Nomenclatura Química e Representação de estruturas em colaboração com a Divisão de Química Inorgânica da IUPAC. Tradutores: Faria, R. B.; Serra, O. A.; Cardoso, J.; Costa, J. A. L.; Garcia, M. H.; Henriques, R. T.; Herold, B. J.; Magalhães, M. C. F.; Marçalo, J.; Pellegrino, O.); Sociedade Portuguesa de Química: Lisboa, 2017 (ISBN 978-989-848159-7).

-11. Thyssen, P.; Binnemans, K. Em Handbook on the Physics and Chemistry of Rare Earths; Gschneider Jr., K. A., Bünzli, J.-C. G., Pecharsky, V. K., eds.; Elsevier: Amsterdam, 2011, Chap. 248.

12. 1787-1987: Two hundred years of Rare Earths; Gschneidner Jr., K. A., Capellen, J., eds.; Rare-earth Information Center/North-Holland: Ames/ Amsterdam, 1987.

13. Spedding, F. H.; Voigt, A. F.; Gladrow, E. M.; Sleight N. R.; J. Am. Chem. Soc. 1947, 69, 2777.
14. Spedding, F. H.; Voigt, A. F.; Gladrow, E. M.; Sleight N. R.; Powell, J. E.; Wright, J. M.; Butler, T. A.; Figard, P.; J. Am. Chem. Soc. 1947, 69, 2786.

15. Spedding, F. H.; Fulmer, E. I.; Butler, T. A.; Gladrow, E. M.; Gobush, M.; Porter, P. E.; Powell, J. E.; Wright, J. M.; J. Am. Chem. Soc. 1947, 69, 2812.

16. Extractive Metallurgy of Rare Earths; Gupta, C. K., Krishnamurthy, N., eds.; CRC Press: Boca Raton, 2004.

17. Lanthanide Probes in Life, Chemical and Earth Sciences; Bünzli, J.-C. G., Choppin, G. R., eds.; Elsevier: Amsterdam, 1989.

18. Eliseeva, S. V.; Bünzli, J.-C. G.; New J. Chem. 2011, 35, 1165.

19. Huang, X.; Han, S.; Huang, W.; Liu, X.; Chem. Soc. Rev. 2013, 42, 173.

20. Ying, T.-K.; Gao, X.-P.; Hu, W.-K.; Wu, F.; Noréus, D.; Int. J. Hydrogen Energy 2006, 31, 526.

21. Jüstel, T.; Möller, S.; Winlker, H.; Adam, W. Em Ullmanns's Encyclopedia of Industrial Chemistry, John Wiley \& Sons: Weinheim, 2012.

22. Feldmann, C.; Jüstel, T.; Ronda, C.; Schmidt, P.; Adv. Funct. Mater. 2003, 13, 511.

23. Höppe, H. A.; Angew. Chem., Int. Ed. 2009, 48, 3572.

24. Ying, T.-K.; Gao, X.-P.; Hu, W.-K.; Wu, F.; Noréus, D.; Int. J. Hydrogen Energy 2006, 31, 526.

25. Tanaka, T.; Kuzuhara, M.; Watada, M.; Oshitani, M.; J. Alloys Compd. 2006, 408-412, 323.

26. Nieto, A.; Guelly, K.; Kleit, A.; Resour. Policy 2013, 38, 496.

27. de Sousa Filho, P. C.; Gomes, L. F.; de Oliveira, K. T.; Neri, C. R.; Serra, O. A.; Appl. Catal., A 2009, 360, 210.

28. Nascimento, L. F.; Martins, R. F.; Silva, R. F.; de Sousa Filho, P. C.; Serra, O. A.; React. Kinet., Mech. Catal. 2014, 111, 149.

29. Nascimento, L. F.; de Sousa Filho, P. C.; Lima, J. F.; Serra, O. A.; J. Braz. Chem. Soc. 2015, 26, 1315.

30. https://roskill.com/market-report/rare-earths/, acessado em novembro de 2019.

31. Balaram, V.; Geosci. Front. 2019, 10, 1285.

32. Grasso, V. B.; Rare Earth Elements in National Defense: Background, Oversight Issues, and Options for Congress; Congressional Research Service: Washington, D. C., 2013.

33. Binnemans, K.; Jones, P. T.; Blanpain, B.; van Gerven, T.; Yang, Y.; Walton, A.; Buchert, M.; J. Clean. Prod. 2013, 51, 1.

34. Tan, Q.; Li, J.; Zeng, X.; Crit. Rev. Environ. Sci. Technol. 2015 45, 749.

35. Migaszewski, Z.; Gałuszka, A.; Crit. Rev. Environ. Sci. Technol. 2015, $45,429$.

36. Serra, O. A.; J. Braz. Chem. Soc. 2011, $22,811$.

37. Szabadvary, F. Em Handbook on the Physics and Chemistry of Rare Earths; Gschneider Jr., K. A., Eyring, L., eds.; Elsevier: Amsterdam, 1988, Chap. 73.

38. Mikhailov, O. V.; Rev. Inorg. Chem. 2019, 39, 2.

39. Constable, E. C.; Dalton Trans. 2019, 48, 9408.

40. Mendeleev, D.; Liebigs Ann. Chem. 1871, Supplementband 8, 133.

41. Fontani, M.; Costa, M.; Orna, M. V.; The Lost Elements: The Periodic Table's Shadow Side; Oxford University Press: New York, 2015.

42. Meyer, S.; Phys. Z. 1918, 19, 178.

43. Heilbron, J. L.; H. G. J. Moseley: The Life and Letters of an English Physicist, University of California Press: Berkeley-Los Angeles, 1974.

44. Thomsen, J.; Z. Anorg. Chem. 1895, 9, 190.

45. Bohr, N.; The Structure of the Atom. Nobel Prize Lecture, 1922. (disponível em https://www.nobelprize.org/prizes/physics/1922/bohr/ lecture/, acessado em novembro de 2019).

46. Kauffman, G. B.; Alfred Werner: Founder of Coordination Chemistry; Springer-Verlag: Berlin-Heidelberg, 1966.

47. Werner, A.; Ber. Dtsch. Chem. Ges. 1905, 38, 914.

48. Davis, H. M.; Seaborg, G. T.; The Chemical Elements, $3^{\text {rd }}$ ed., Science Service: Washington, D. C., 1961. 
49. https://iupac.org/wp-content/uploads/2018/12/IUPAC_Periodic_Table01Dec18.pdf, acessado em novembro de 2019.

50. Lucas, S.; Tese de Doutorado, Faculté des Sciences et Techniques, Université de Limoges, Limoges, 2003.

51. Rosental, S.; em da Luz, A. B.; Lins, F. A. F.; Rochas \& Minerais Industriais: usos e especificações, $2^{\mathrm{a}}$ ed., CETEM-MCT: Rio de Janeiro, 2008.

52. Stock J. T.; J. Chem. Educ. 1991, 68, 801.

53. Santos, P. C. M.; Dissertação de Mestrado, Instituto de Geociências, Universidade Estadual de Campinas, Campinas, 2009.

54. Leonardos, O. H.; Geociências no Brasil: a contribuição britânica; Forum Editora: Rio de Janeiro, 1970

55. The Brazilian Review, Vol. 2, nº26, Rio de Janeiro, 27 de junho de 1899. (disponível online em http://memoria.org.br/, acessada em novembro 2019).

56. Overstreet, W. C.; The Geologic Ocurrence of Monazite, Geological Survey Professional Paper Vol. 530: Washington, D. C., 1967.

57. The Brazilian Review, Vol. 1, nº38, Rio de Janeiro, 15 de novembro de 1898. (disponível online em http://memoria.org.br/, acessada em novembro 2019).

58. The Brazilian Review, Vol. 3, $\mathrm{n}^{\circ} 47$, Rio de Janeiro, 20 de novembro de 1900. (disponível online em http://memoria.org.br/, acessada em novembro 2019).

59. Kithil, K. L.; Chem. News 1916, 114, 167.

60. The Brazilian Review, Vol. 6, $\mathrm{n}^{\circ} 13$, Rio de Janeiro, 25 de setembro de 1917. (disponível online em http://memoria.org.br/, acessada em novembro 2019).

61. The Brazilian Review, Vol. 6, $\mathrm{n}^{\circ} 17$, Rio de Janeiro, 23 de outubro de 1917. (disponível online em http://memoria.org.br/, acessada em novembro 2019).

62. Shipbuilding and Shipping Record, Londres, 6 de Setembro de 1917. (disponível online em https://archive.org/details/ n10shipbuildings10londuoft, acessado em novembro 2019).

63. Mertie Jr., J. B.; Monazite Deposits of the Southeastern Atlantic States, Geological Survey Circular: Washington, D. C., 1953.

64. Haxel, G. B.; Hedrik, J. B.; Orris, G. J.; Stauffer, P. H.; Hendley II, J. W.; USGS Fact Sheet 2002, 087-02, 4p.

65. Vichi, E. J. S.; Quim. Nova 1983, 6, 152.

66. Santos, P. S.; J. Alloys Compd. 2002, 344, 2.

67. Krumholz, P.; Rev. Sci. Instr. 1951, 22, 362.

68. Krumholz, P.; Spectrochim. Acta 1958, 10, 269.

69. Krumholz, P.; Spectrochim. Acta 1958, 10, 274.

70. Krumholz, P.; J. Phys. Chem. 1959, 63, 1313.

71. Bril, K.; Bril, S.; Krumholz, P.; J. Phys. Chem. 1959, 63, 256.

72. Lainetti, P. E. O.; Freitas, A. A.; Mindrisz, A. C.; Review of Brazilian activities related to the thorium fuel cycle and production of thorium compounds at IPEN-CNEN/SP; International Nuclear Atlantic Conference - INAC2013, Recife, 2013.

73. Lapido-Loureiro, F. E. V.; Terras-raras no Brasil: Depósitos, Recursos Identificados, Reservas, CETEM/CNPq: Rio de Janeiro, 1994.

74. Lapido-Loureiro, F. E. V.; O Brasil e a Reglobalização da Indústria das Terras Raras, CETEM/CNPq: Rio de Janeiro, 2013.

75. Lemos, S. C. S.; Nossol, E.; Ferrari, J. L.; Gomes, E. O.; Andres, J.; Gracia, L.; Sorribes, I.; Lima, R. C.; Inorg. Chem. 2019, 58, 11738.

76. Ullah, S.; Ferreira-Neto, E. P.; Hazra, C.; Parveen, R.; Rojas-Mantilla, H. D.; Calegaro, M. L.; Serge-Correales, Y. E.; Rodrigues-Filho, U. P.; Ribeiro, S. J. L.; Appl. Catal., B 2019, 243, 121.

77. de Sousa Filho, P. C.; Lima, J. F.; Serra, O. A.; J. Braz. Chem. Soc. 2015, 26, 2471.

78. Teo, R. D.; Termini, J.; Gray, H. B.; J. Med. Chem. 2016, 13, 6012.

79. Balasundram, V.; Ibrahim, N.; Kasmani, R. M., Isha, R.; Hamid, M. K. A.; Hasbullah, H.; Ali, R. R.; Appl. Energy 2018, 220, 787.

80. Venturini Filho, E. V.; de Sousa Filho, P. C.; Serra, O. A.; Weber, I. T.; Lucena, M. A. M.; Luz, P. P.; J. Lumin. 2018, 202, 89.
81. Gurgel, G. M.; Lovisa, L. X.; Pereira, L. M.; Motta, F. V.; Li, M. S.; Longo, E., Paskocimas, C. A., Bomio, M. R. D.; J. Alloys Compd. 2017, $700,130$.

82. Bim, L. F. B.; Stucchi, E. B., Cebim, M. A.; J. Lumin. 2018, 203, 105.

83. van Loy, S.; Binnemans, K.; van Gerven, T.; Engineering 2018, 4, 398.

84. Deichmann, V. A. F.; Novo, J; B; M.; Cirpan, A.; Karaszb, F. E.; Akcelrud, L.; J. Braz. Chem. Soc. 2007, 18, 330.

85. Chaudan, E.; Kim, J.; Tusseau-Nenez, S.; Goldner, P.; Malta, O. L.; Peretti, J.; Gacoin, T.; J. Am. Chem. Soc. 2018, 140, 9512.

86. Grzyb, T.; Szczeszak, A.; Shyichuk, A.; Moura, Jr., R. T.; Carneiro Neto, A. N.; Andrzejewska, N.; Malta, O. L.; Lis, S.; J. Alloys Compd. 2018, $741,459$.

87. Machado, I. P.; Pedroso, C. C. S.; de Carvalho, J. M.; Teixeira, V. C.; Rodrigues, L. C. V.; Brito, H. F.; Scripta Mater. 2019, 164, 57.

88. de Carvalho, J. M.; Pedroso, C. C. S.; Machado, I. P.; Hölsä, J.; Rodrigues, L. C. V.; Głuchowski, P.; Lastusaari, M.; Brito, H. F.; J. Mater. Chem. C 2018, 6, 8897.

89. Bispo, Jr., A. G.; Lima, S. A. M.; Lanfredi, S.; Praxedes, F. R.; Pires, A. M.; J. Lumin. 2019, 214, 116604.

90. Pinatti, I. M.; Pereira, P. F. S.; de Assis, M.; Longo, E.; Rosa, I. L. V.; J. Alloys Compd. 2019, 771, 433.

91. Pereira, P. F. S.; Santos, C. C.; Gouveia, A. F.; Ferrer, M. M.; Pinatti, I. M.; Botelho, G.; Sambrano, J. R.; Rosa, I. L. V.; Andrés, J.; Longo, E.; Inorg. Chem. 2017, 56, 7360.

92. Silva Filho, C. I.; Oliveira, A. L.; Pereira, S. C. F.; de Sá, G. F.; da Luz, L. L.; Alves Jr., S.; Dalton Trans. 2019, 48, 2574.

93. Soares, J. C.; Siqueira, K. P. F.; de Sousa Filho, P. C.; Moreira, R. L.; Dias, A.; Dalton Trans. 2017, 46, 825.

94. Moura, A. L.; Maia, L. J. Q.; Jerez, V.; Gomes, A. S. L; de Araújo, C. B.; J. Lumin. 2019, 214, 116543.

95. Oliveira, M. C.; Pontes Ribeiro, R.; Gracia, L.; de Lazaro, S. R.; de Assis, M.; Oliva, M.; Rosa, I. L. V.; Gurgel, M. F. C.; Longo, E.; Andrés, J.; CrystEngComm 2018, 20, 5519.

96. Joaquim, F. L. S.; Rocha, L. A.; Nascimento Jr., C. S.; Esbenshade, J.; Schiavon, M. A.; Ferrari, J. L.; J. Alloys Compd. 2019, 774, 694.

97. Pereira, P. F. S.; de Moura, A. P.; Nogueira, I. C.; Lima, M. V. S.; Longo, E.; de Sousa Filho, P. C.; Serra, O. A.; Nassar, E. J.; Rosa, I. L. V.; J. Alloys Compd. 2012, 526, 11.

98. Ferrari, J. L.; Pires, A. M.; Davolos, M. R.; Mater. Chem. Phys. 2009, 113, 587.

99. Correales, Y. E. S.; Hazra, C.; Ullah, S.; Lima, L. R.; Ribeiro, S. J. L.; Nanoscale Adv. 2019, 1, 1936.

100. Monteiro, J. H. S. K.; Dutra, J. D. L.; Freire, R. O.; Formiga, A. L. B.; Mazali, I. O.; de Bettencourt-Dias, A.; Sigoli, F. A.; Inorg. Chem. 2018, 57, 15421.

101. Assunção, I. P.; Carneiro Neto, A. N.; Moura, Jr.; R. T.; Pedroso, C. C. S.; Silva, I. G. N.; Felinto, M. C. F. C.; Teotonio, E. E. S.; Malta, O. L.; Brito, H. F.; ChemPhysChem 2019, 20, 1931.

102. Cunha, C. S.; Köppen, M.; Terraschke, H.; Friedrichs, G.; Malta, O. L.; Stock, N.; Brito, H. F.; J. Mater. Chem. C 2018, 6, 12668.

103. Pires, G. P.; Costa, I. F.; Brito, H. F.; Faustino, W. M.; Teotonio, E. E. S.; Dalton Trans. 2016, 45, 10960.

104. Pugina, R. S.; da Rocha, E. G.; Ribeiro, S. J. L.; Caiut, J. M. A.; J. Lumin. 2019, 205, 423.

105. de Oliveira, T. C.; Santos, H. P.; Lahoud, M. G.; Franco, D. F.; Freire, R. O.; Dutra, J. D. L.; Cuin, A.; de Lima, J. F.; Marques, L. F.; J. Lumin. 2017, 181, 196.

106. Adati, R. D.; Monteiro, J. H. S. K.; Cardoso, L. P.; de Oliveira, D. H.; Jafelicci, Jr., M.; Davolos, M. R.; J. Braz. Chem. Soc. 2019, 30, 1707.

107. Scott, M. C.; de Souza, G. D.; Ciuffi, K. J.; de Faria, E. H.; Rocha, L. A.; Nassar, E. J.; Micropor. Mesopor. Mat. 2019, 277, 179.

108. Mutti, A. M. G.; Santos, J. A. O.; Cavalcante, D. G. S. M.; Gomes, A. S.; Job, A. E.; Pires, A. M.; Lima, S. A. M.; Opt. Mater. 2019, 90, 57. 
109. Rajesh, D.; de Camargo, A. S. S.; J. Lumin. 2019, 207, 469.

110. Alves, C. C.; Ribeiro, S. J. L.; Mendonça, C. R.; de Boni, L.; Caiut, J. M. A.; J. Lumin. 2019, 211, 436.

111. Carlos, L. D.; Ferreira, R. A. S.; Bermudez, V. D.; Ribeiro, S. J. L.; $A d v$. Mater. 2009, 21, 509.

112. Sales, T. O.; Amjad, R. J.; Jacinto, C.; Dousti, M. R.; J. Lumin. 2019, 205, 282.

113. Rivera, V. A. G.; Ferri, F. A.; Gehlen, M. H.; Nunes, L. A. O.; Marega, Jr., E.; Opt. Eng. 2018, 57, 085102.

114. Manzani, D.; Souza Junior, J. B.; Reyna, A. S.; Silva Neto, M. L.; Bautista, J. E. Q.; Ribeiro, S. J. L.; de Araújo, C. B.; Dalton Trans. 2019, $48,6261$.

115. Khan, L. U.; da Silva, G. H.; de Medeiros, A. M. Z.; Khan, Z. U.; Gidlund, M.; Brito, H. F.; Moscoso-Londoño, O.; Muraca, D.; Knobel, M.; Pérez, C. A.; Martinez, D. S. T.; ACS Appl. Nano Mater. 2019, 2, 3414.

116. Khan, L. U.; Zambon, L. F. M.; Santos, J. L.; Rodrigues, R. V.; Costa, L. S.; Muraca, D.; Pirota, K. R.; Felinto, M. C. F. C.; Malta, O. L.; Brito, H. F.; ChemistrySelect 2018, 3, 1157.

117. Dutra, J. D. L.; Bispo, T. D.; Freire, R. O.; J. Comput. Chem. 2014, 34, 772.

118. Rodrigues, N. M.; Daniel, C. R. A.; Rodrigues, E. S. M.; da Costa, Jr., N. B.; Gimenez, I. F.; Freire, R. O.; J. Mol. Strcut. 2019, 1184, 310.

119. Silva, A. I. S.; Lima, N. B. D.; Simas, A. M.; Gonçalves, S. M. C.; ACS Omega 2017, 2, 6786

120. Silva, F. T.; Lins, S. L. S.; Simas, A. M.; Inorg. Chem. 2018, 57, 10557.

121. Souza, A. S.; Cortes, G. K. R.; Lima, H.; Couto dos Santos, M. A.; J. Lumin. 2019, 210, 452.

122. He, L.; Ji, W., Yin, Y., Sun, W.; J. Rare Earths 2018, 16, 108.

123. Hidayah, N. N.; Abidin, A. Z.; Miner. Eng. 2018, 121, 146.

124. Xiao, C.; Huang, K. Cao, W.; Dong, T.; Li, M.; Liu, H.; Chem. Eng. Res. Des. 2018, 19, 132.

125. Shirayama, S.; Okabe, T. H.; Metall. Mater. Trans. 2018, 49, 1067.

126. Akcil, A.; Akhmadiyeva, N.; Abdulvaliyev, R.; Meshram, A. P.; Miner. Process. Extr. Metall. Rev. 2018, 39, 145.

127. Valentina, I.; Maria, I. N.; Loris, P.; Marcello, C.; Luigi, P.; Francesco, V.; J. Clean. Prod. 2018, 172, 2840.

128. Yoon, H.-S.; Kim, C.-J.; Chung, K. W.; Kim, S.; Kumar, J. R.; J. Braz. Chem. Soc. 2015, 26, 1144.

129. Blasse, G.; Grabmaier, B. C.; Luminescent Materials, Springer-Verlag: Berlin, 1994.

130. Panayotova, M.; Panayotov, V.; Annual of the University of mining and geology St. Ivan Rilski 2012, vol. 55, Part II, 142. (disponível online em http://www.mgu.bg/sessions/12/02/mpvp.pdf, acessado em novembro 2019).

131. http://www.mining.com/mountain-pass-sells-20-5-million, acessado em novembro 2019.

132. http://recola.fbk.eu/, acessado em novembro 2019.

133. Yurramendi, L.; Gijsemans, L.; Forte, F.; Aldana, J. L.; del Río, C.; Binnemans, K.; Hydrometallurgy 2019, 187, 38.

134. Binnemans, K.; Jones, P. T.; J. Rare Earths 2014, 32, 195.

135. Jowitt, S. M.; Werner, T. T.; Weng, Z.; Mudd, G. M.; Curr. Opin. Green Sust. Chem. 2018, 13, 1.
136. Royen, H.; Fortkamp, U.; Rare Earth Elements- Purification, Separation and Recycling, IVL Swedish Environmental Research Institute: Stockholm, 2016.

137. Gijsemans, L.; Forte F.; Onghena B.; Binnemans K.; RSC Adv. 2018, 8 , 26349 ,

138. Takahashi, T.; Takano, A.; Saito, T.; Nagano, N.; Harai, S.; Shimakage, K.; J. Min. Process. Inst. 2001, 117, 579.

139. Hirajima, T.; Sasaki, K.; Bissombolo, A.; Hirai, H.; Hamada, M.; Tsunekawa, M.; Sep. Purif. Technol. 2005, 44, 197.

140. Hirajima, T.; Bissombolo, A.; Sasaki, K.; Nakayama, K.; Hirai, H.; Tsunekawa, M.; Int. J. Miner. Process. 2005, 77, 187.

141. Plank, C. J.; Rosinski, E. J.; Catalytic hydrocarbon conversion with a crystalline zeolite composite catalyst. Patent Application US 3140253A, 1964.

142. Zhan, W.; Guo, Y.; Gong, X.; Guo, Y.; Wang, Y.; Lu, G.; Chin. J. Catal. 2014, 35, 1238

143. Yoo, J. S.; Catal. Today 1998, 44, 27.

144. Rosário, J.; da Luz, L. L.; Geris, R.; Ramalho, J. G. S.; da Silva, A. F.; Alves Jr., S.; Malta, M.; Sci. Rep. 2019, 9, 7302.

145. de Assis, S. G. F.; Santos, G. C.; Santos, A. B. S.; Falcão, E. H. L.; Viana, R. S. V.; Alves Junior, S.; J. Sol. State Chem. 2019, 276, 309.

146. Barbosa, C. D. E. S.; da Luz, L. L.; Almeida Paz, F. A.; Malta, O. L.; Rodrigues, M. O.; Ferreira, R. A. S.; Carlos, L. D.; RSC Adv. 2017, 7, 6093.

147. Serwy, S. B.; Wanderley, K. A.; Lucena, M. A. M.; Maldaner, A. O.; Talhavini, M.; Rodrigues, M. O.; Weber, I. T.; J. Lumin. 2018, 200, 24.

148. Bim Junior, O.; Bedran-Russo, A.; Flor, J. B. S.; Borges, A. F. S.; Ximenes, V. F.; Frem, R. C. G.; Lisboa-Filho, P. N.; New J. Chem. 2019, 43, 1017.

149. Alves Jr., S.; Metal Organic Frameworks (MOFs): da sintese a aplicações em meio ambiente, saúde e segurança pública, CRV: Curitiba, 2016.

150. Galaço, A. R. B. S., de Lima, J. F., Serra, O. A.; Quim. Nova, 2018, 41, 678.

151. Galaço, A. R. B. S., Donatoni, M. C., Walton, R. I., de Oliveira, K. T., Serra, O. A.; Chem. Commun. 2019, 55, 8106.

152. Tanabe, K. K.; Cohen, S. M.; Chem. Soc. Rev. 2011, 40, 498.

153. Cui, Y.; Xu, H.; Yue, Y.; Guo, Z.; Yu, J.; Chen, Z.; Gao, J.; Yang, Y.; Qian, G.; Chen, B.; J. Am. Chem. Soc. 2012, 134, 3979.

154. Brunet, G.; Marin, R.; Monk, M.-J.; Resch-Genger, U.; Gálico, D. A.; Sigoli, F. A.; Suturina, E. A.; Hemmer, E.; Murugesu, M.; Chem. Sci. 2019, 10, 6799.

155. Rodrigues, E. M.; Gálico, D. A.; Mazali, I. O.; Sigoli, F. A.; Sensors Actuators, A 2019, 291, 1.

156. de Sousa Filho, P. C.; Alain, J.; Leménager, G.; Larquet, E.; Fick, J.; Serra, O. A.; Gacoin, T.; J. Phys. Chem. C 2019, 123, 2441.

157. Ximendes, E. C.; Pereira, A. F.; Rocha, U.; Silva, W. F.; Jaque, D.; Jacinto, C.; Nanoscale 2019, 11, 8864

158. del Rosal, B.; Ximendes, E.; Rocha, U.; Jaque, D.; Adv. Opt. Mater. 2017, 5, 1600508.

159. Davies, B. E.; Mottram, R. S.; Harris, I. R.; Mater. Chem. Phys. 2001, 6, 272.

160. Zakotnik, M.; Tudor, C. O.; Waste Manage. 2015, 44, 48. 